\title{
The role of PfEMP1 as targets of naturally acquired immunity to childhood malaria: prospects for a vaccine
}

\author{
PETER C. BULL ${ }^{1,2}$ and ABDIRAHMAN I. ABDI ${ }^{1,3}$ \\ ${ }^{1}$ Department of Pathology, University of Cambridge, Tennis Court Rd, Cambridge CB2 1QP, UK \\ ${ }^{2}$ Nuffield Department of Medicine Research Building, Centre for Tropical Medicine and Global Health, University of \\ Oxford, Old Road Campus, Roosevelt Drive, Headington, Oxford OX3 7FZ, UK \\ ${ }^{3}$ Department of Biochemistry and Chemistry, Pwani University, P.O. Box 195, 80108 Kilifi, Kenya
}

(Received 1 April 2015; revised 19 August 2015; accepted 23 August 2015; first published online 7 Fanuary 2016)

SUMMAR Y

The Plasmodium falciparum erythrocyte membrane protein 1 antigens that are inserted onto the surface of $P$. falciparum infected erythrocytes play a key role both in the pathology of severe malaria and as targets of naturally acquired immunity. They might be considered unlikely vaccine targets because they are extremely diverse. However, several lines of evidence suggest that underneath this molecular diversity there are a restricted set of epitopes which may act as effective targets for a vaccine against severe malaria. Here we review some of the recent developments in this area of research, focusing on work that has assessed the potential of these molecules as possible vaccine targets.

Key words: malaria, immunity, vaccine, variant surface antigens, PfEMP1.

\section{INTRODUCTION}

When Plasmodium falciparum infect human erythrocytes, they insert into the erythrocyte surface parasite antigens that profoundly alter the antigenic properties of the cells (Langreth and Reese, 1979). These antigens play a central role in the pathology of severe malaria by mediating the cytoadhesion to various molecules on host cells (Rowe et al. 2009) and sequestration of parasites in tissues including the brain, long known as a hallmark of fatal falciparum malaria in humans (Marchiafava and Bignami, 1894). One of their key features is that they undergo antigenic variation (Roberts et al. 1992) and for this reason they are collectively called variant surface antigens (VSA).

The feasibility of developing a malaria vaccine is supported by the observation that children growing up in malaria endemic areas develop naturally acquired immunity to malaria after several years of exposure (Wilson et al. 1950). This immunity protects children from severe life threatening malaria and promotes the establishment of chronic, asymptomatic infections, to which even individuals growing up in malaria endemic areas remain susceptible for life (Marsh, 1992). In this review, we will focus on the role of the $P$. falciparum membrane protein 1 (PfEMP1) family of VSA as targets of naturally acquired immunity and review their potential as vaccine targets. There have been extremely encouraging developments in this area of research over the last 3 years. However, as our knowledge grows,

* Corresponding author: Peter Bull, Department of Pathology, University of Cambridge, Tennis Court Rd, Cambridge CB2 1QP, UK. E-mail: pb642@cam.ac.uk so does our appreciation of the complexity of the parasite's strategy of evading our immune systems. There are no shortage of recent reviews that together give a comprehensive summary of variants surface antigens both in immunity and cytoadhesion (Rowe et al. 2009; Chan et al. 2014; Smith, 2014). Here, we will give an overview of what we think are the current key questions and gaps in our knowledge.

\section{VSA are important targets of naturally acquired immunity}

An early demonstration of the importance of VSA as immune targets was a serological study showing that, among seven different anti-blood stage assays including one measuring opsonization of infected erythrocytes, the titre in children's serum of antibodies that agglutinated infected erythrocytes from a single donor, was the only assay associated with reduced future experience of clinical malaria (Marsh et al. 1989). This apparent protection by anti-VSA antibodies against future disease is supported by more recent longitudinal studies by Dodoo et al. (2001), where antibodies to infected erythrocytes of $2 / 5$ parasite isolates showed a clear association with protection after age correction. Measures of antibodies to the infected erythrocyte surface present at the time of infection also show a negative association with the severity of disease, supporting a role in immunity (Tebo et al. 2002; Yone et al. 2005). Consistent with this, chronic asymptomatic infections are associated with particularly high levels of antibodies to VSA and individuals who carry asymptomatic infections but do not make 
such responses tend to be more susceptible to future clinical malaria (Bull et al. 2002; Kinyanjui et al. 2004; Mackintosh et al. 2008). The third approach used in early epidemiological studies was to test for carriage of antibodies that reverse cytoadhesion. The rosetting phenotype, defined as the binding of infected erythrocytes to uninfected erythrocytes, provides a good example. Carlson et al. (1990) found an association between the presence in children's serum of antibodies that reverse rosetting of a laboratory-adapted parasite line and (1) reduced rosetting in the children's own parasites and (2) absence of cerebral malaria. Antigen variants expressed on the surface of parasites from children with malaria was later shown to correspond with gaps in the repertoire of antibodies carried by the infected individual before they became ill (Bull et al. 1998; Giha et al. 2000). Together, these data support a model of naturally acquired immunity to malaria through the gradual acquisition of many variant specific antibodies to VSA.

Such a model is consistent with the known dynamics of $P$. falciparum infections through information gathered during the time when malaria was used in the therapy of neurosyphilis (Whitrow, 1990; Karamanou et al. 2013). The importance of VSA as targets of naturally acquired immunity to malaria is highlighted by the observation of clear recrudescence in parasitaemia followed by rapid decline. When these recrudescence occured, they did so with relatively consistent initial growth rates suggesting that new variants were emerging and were subsequently controlled on an otherwise only gradually changing immunological background (Molineaux et al. 2001).

Plasmodium falciparum encodes several multigene families including var, rif and stevor for which there is evidence of expression on the surface of parasite-infected erythrocytes (Baruch et al. 1995; Smith et al. 1995; Su et al. 1995; Cheng et al. 1998; Fernandez et al. 1999; Kyes et al. 1999; Niang et al. 2014; Goel et al. 2015). Rif and stevor together with the majority of the 60 genes that make up the var gene family are located in the highly diverse sub-telomeric regions of chromosomes (Gardner et al. 2002). Of these families the var genes and the PfEMP1 antigens they encode have been the subject of the most research to date because of the role that PfEMP1 play both in cytoadhesion to many specific host receptors and the evidence for their role as targets of naturally acquired antibodies that undergo clonal antigenic variation.

An early study demonstrated how changes in PfEMP1 expression by a laboratory parasite line correlated with switches in both the antigenic and cytoadhesive properties of the infected erythrocyte surface (Biggs et al. 1991). After the var genes had been identified (Baruch et al. 1995; Smith et al.
1995; Su et al. 1995), switches in var gene expression were correlated with both antigenic variation and altered ability of the parasites to bind to the host receptor molecule ICAM1 (Smith et al. 1995). Many known host-cell-binding phenotypes identified in $P$. falciparum-infected erythrocytes have since been mapped onto regions of PfEMP1, including ICAM1 (Smith et al. 2000; Bengtsson et al. 2013), CD36 (Baruch et al. 1997; Smith et al. 1998; Robinson et al. 2003), complement receptor 1 (Rowe et al. 1997), heparin, blood group A antigen (Vigan-Womas et al. 2012), Chondroitin sulphate A (Salanti et al. 2003), PECAM1 (Berger et al. 2013), IgM (Ghumra et al. 2008) and endothelial protein C receptor (EPCR) (Turner et al. 2013). Recently, knockdowns of var gene expression in two laboratory lines resulted in almost complete loss of antibody recognition and cytoadhesive properties (Chan et al. 2012), suggesting that PfEMP1 are the dominant antigens expressed on the surface of these laboratory-adapted parasite lines that are recognized by naturally acquired antibodies against infected erythrocytes.

\section{Why is the feasibility of a PfEMP1 vaccine worth exploring?}

PfEMP1 clearly plays an important role in the hostparasite interaction. However, PfEMP1 is, on the face of it, perhaps the last group of proteins that you might want to study as a malaria vaccine candidate. Early serological studies show that after an episode of disease, children develop antibodies that are highly specific to the parasites that caused that disease episode, suggesting that, at least the immune-dominant epitopes expressed on the infected erythrocyte surface are extremely diverse (Marsh and Howard, 1986; Forsyth et al. 1989; Iqbal et al. 1993; Reeder et al. 1994; Bull et al. 1999). Though they are encoded by a family of only 60 var genes in every genome, each genome is potentially a drop in the ocean of var diversity within the global parasite population and the potential for immune evasion through influx of new PfEMP1 variants through gene conversion would seem from these data to be immense. Barry et al. (2007), sampled short tags of sequence from PfEMP1 from a worldwide collection of parasites and failed to find a limit to this sequence diversity. As new sequences were sampled randomly from the 'pot' of collected sequences, a point was never reached at which the rate of sampling of new sequences diminished (Barry et al. 2007). Recent evidence further suggests that var undergo mitotic recombination, potentially unpacking unlimited diversity from a single genome (Claessens et al. 2014).

Despite this immense molecular diversity children as they grow up in malaria endemic areas do learn to recognize antigens expressed on the surface of 
infected erythrocytes (Barragan et al. 1998; Bull et al. 1998) and cross-reactivity exists between epitopes expressed on the surface of infected erythrocytes sampled from different geographical areas and even different continents (Aguiar et al. 1992; Nielsen et al. 2004). So why does antigenic variation in $P$. falciparum not always lead to infections that overwhelm the host? The life cycle of P. falciparum relies on the establishment of chronic blood stage infections and host survival through the dry season when pools of water necessary for mosquito reproduction are scarce and opportunities to transmit to mosquitos is low. The question of how the correct balance is maintained between too little and too much antigenic diversity; host survival and parasite escape from antibodies, is still one of the major questions in malaria parasite biology (Saul, 1999). The generally accepted broad explanation is that antigenic diversity in PfEMP1 is constrained by its function in cytoadhering to host cells and bringing about sequestration of infected erythrocytes in tissue capillary beds and that inefficient cytoadhesion leads to passage of the infected erythrocytes through the spleen where they are removed from circulation (Barnwell et al. 1983).

The idea that the functional role of PfEMP1 constrains its antigenic diversity forms an important part of the rationale for considering PfEMP1 as a viable vaccine target against severe malaria (see Fig. 1). This rationale stems from the way in which naturally acquired immunity develops. Children who grow up in malaria endemic areas probably never develop sterile immunity to $P$. falciparum. Immunity to severe malaria develops more rapidly than immunity to mild malaria as the host-parasite relationship changes from one associated with severe malaria and transmission to mosquitoes towards one that sustains chronic asymptomatic infections (Langhorne et al. 2008; Goncalves et al. 2014; Griffin et al. 2015). If constraints on PfEMP1 structure are imposed by effective cytoadhesion and avoidance of the host spleen, this could result in trade-off between antigenic novelty on the one hand and highly effective cytoadhesion on the other (Bull et al. 1999; Nielsen et al. 2002; Jensen et al. 2004; Frank and Bush, 2007; van Noort et al. 2010; Buckee and Recker, 2012; Severins et al. 2012). If only strongly cytoadhesive PfEMP1 can mediate the level of sequestration that can bring about severe malaria and these variants are more structurally constrained and antigenically conserved, then it is possible to imagine this trade-off setting up a spectrum of variants differentially adapted to efficient cytoadhesion on the one hand and antibody evasion on the other. The observed shift in host-parasite interaction observed in children growing up exposed to malaria parasites could be brought about through rapid acquisition of immunity to the few types that support high levels of cytoadhesion and differential survival of parasites expressing

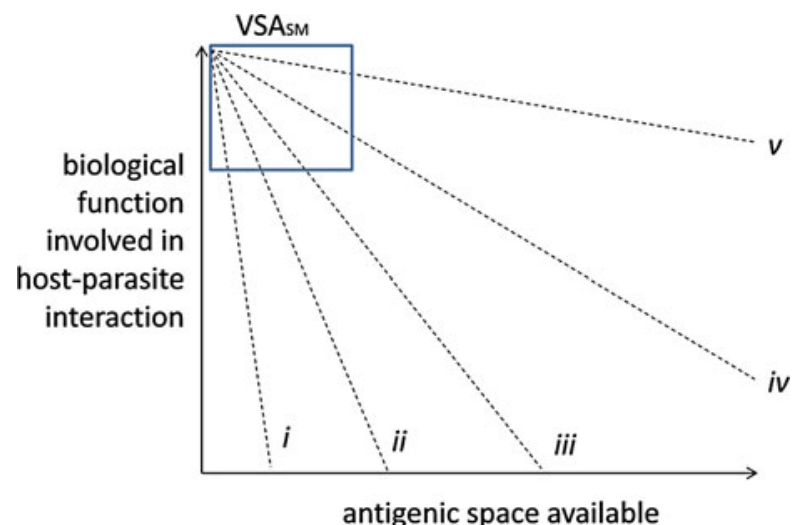

Fig. 1. Hypothetical trade-offs between function and antigenic novelty. This figure shows an immunological version of the principle of functional constraint focusing on efficiency of biological functions associated with the host-parasite interaction ( $y$-axis) and the hypothetical antigenic space within which those functions exist ( $x$-axis). Optimal function can only be performed by a narrow range of molecular structures which translates, in the simplest case, to a small antigenic space. Key to virulence is not simply the function itself, but the ability of molecules or systems of molecules to uncouple immunogenicity from function to expand the antigenic space available.

Hypothetical lines are drawn to suggest trade-offs between function and antigenic space in for: (i) Measles haemagglutinin (Frank and Bush, 2007), (ii) var2CSA, (iii) group A and DC8 PfEMP1 (Buckee and Recker, 2012), (iv) group B and C PfEMP1, (vi) HIV gp120 (de Boer and Boerlijst, 1994). Following from this hypothetical trade-off, parasites with high levels of recognition by antibodies commonly carried by children have been proposed to express PfEMP1 variants with strong cytoadhesive function and exist within a small restricted immunological space. Such hypothetical variants have been called: agglutination frequency high $\left(\mathrm{AF}^{\mathrm{H}}\right.$ (Bull et al. 2000) VSA with a high frequency of

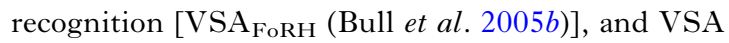
associated with severe malaria [VSA SM $_{\text {(Nielsen } \text { et al. }}$ 2002; Jensen et al. 2004)]. Their position within the graph is indicated with a box

variants that can only support uncomplicated and asymptomatic infections.

Evidence for this model comes first from the association between various cytoadhesion phenotypes and the severity of malaria (Carlson et al. 1990; Rowe et al. 1995; Newbold et al. 1997; Heddini et al. 2001; Ochola et al. 2011; Turner et al. 2013). The second line of evidence comes from studies that have examined variation in the serological commonness of antigens expressed on the surface of infected erythrocytes measured by panels of plasma or serum. Parasites from children with severe malaria and those who were very young tend to be more commonly recognized (Bull et al. 1999, 2000; Nielsen et al. 2002). The fact that severe malaria is a rare manifestation of infection seems at odds with the idea that it is associated with commonly occurring variants and raises the question of why some 
children get severe malaria and others don't. We might hypothesize that the expression of subsets of commonly circulating PfEMP1 is necessary, if not sufficient, for the development of severe malaria. However, this would be at odds with the observation that parasites from 13/42 children with severe malaria in (Bull et al. 2000) were not agglutinated by any of a panel of 15 children's plasma (Bull et al. 2005b). The serological profiles of commonly recognized parasites were also diverse showing that there may be many commonly recognized types circulating in the parasite population (Bull et al. 1999, 2000, 2005b; Nielsen et al. 2002).

\section{PfEMP1 structure reflects the tension between cytoadhesive function and antigenic novelty}

The structure of PfEMP1 nicely reflects its dual role as an antigenically variant cytoadhesive molecule. Despite considerable molecular diversity and length variation between the PfEMP1 variants, there is underlying structural conservation at various levels. This can be summarized as follows: (1) the molecules are constructed from only two broad classes of domain [see (Higgins and Carrington, 2014) for a recent review]. The most common type of domain, 'duffy binding-like' (DBL) exists in several forms in Plasmodium species, in the duffy blood group binding protein in Plasmodium vivax, and in P. falciparum, the EBA140 and EBA175 erythrocytebinding antigens and in the MSPDBL2 merozoite surface protein. The other domain type found in PfEMP1 is called the 'cysteine-rich interdomain region' (CIDR). (2) Both CIDR and DBL contain blocks of sequence (homology blocks) that are relatively conserved. These homology blocks can be used to divide each domain type into various classes and subclasses (Rask et al. 2010). (3) The key feature of these domain subclasses is that they represent deep divisions within the sequences. These broad classes of domain are commonly encountered between different parasite isolates and antigenic differences found within each parasite genome appear to be broadly conserved (Joergensen et al. 2006, 2007). This is reminiscent of the deep divide seen within MHC genes (Klein and O'Huigin, 1994) and is supported by the existence of a similar range of common sequence features in var sequences from Plasmodium reichenowi, a parasite species similar to $P$. falciparum that infects chimpanzees (Bull et al. 2008; Zilversmit et al. 2013; Otto et al. 2014). In the case of PfEMP1 domains, specific cytoadhesive phenotypes are associated with specific domain subtypes (Fig. 2 and Table 1). (4) Finally, the predicted three-dimensional structures of these domains tends to be conserved and PfEMP1 molecules associated with childhood malaria are thought to exist as loose modular string of domains each with one of two basic structures (Klein et al. 2008; Higgins and Carrington, 2014).
Functional specialization is supported by serological and expression studies

A single clear example shows how effectively evolution has shaped the PfEMP1 repertoire to adapt both immunologically and functionally to its host. Malaria in pregnancy is associated with a single PfEMP1 variant encoded by var2CSA (Salanti et al. 2003, see Box 1). This PfEMP1 binds specifically to chondroitin sulphate A but not to CD36 and is adapted to bind to syncitiotrophoblasts in the placenta. Parasites isolated from placenta are poorly recognized by antibodies from children, male adults and women during their first pregnancy but immunity develops during subsequent pregnancies, explaining the observed parity dependency in susceptibility to placental malaria (Beeson et al. 1999).

This functional specialization shapes the entire PfEMP1 repertoire. PfEMP1 associated with childhood malaria can be divided into three broad groups, A, B and C defined by upstream (ups) elements A, B and C, respectively (Lavstsen et al. 2003). Unlike the majority of var genes, those in group $\mathrm{C}$ are located in clusters close to centromeres. Diversity of var genes is maintained by gene conversion events that occur between non-homologous positions within the genome. As a result the architectures of var genes, that is, the combinations and number of various DBL and CIDR domains, are highly variable between genomes (Kraemer and Smith, 2003). Despite this, the group A genes appear to be relatively genetically isolated from the $\mathrm{B}$ and $\mathrm{C}$ genes. Group A PfEMP1 also tend to be longer and contain more DBL and CIDR domains. In contrast, there is evidence for considerable gene conversion between B and C var genes (Kraemer and Smith, 2003; Kraemer et al. 2007; Rask et al. 2010).

Expression of group A PfEMP1 by the infecting parasite population tends to be associated with infections of children with low immunity. This class of PfEMP1 tends to be recognized first as children are exposed to malaria parasites during the first few years of their lives. Parasites selected in vitro for recognition by pooled children's antibodies have a tendency to express Group A PfEMP1 (Jensen et al. 2004). Recombinant domains from PfEMP1 are recognized in a hierarchical manner and group A PfEMP1 are the first to be recognized (Cham et al. 2009, 2010). Finally, parasite expression of group A-like PfEMP1 is differentially selected against in vivo as children develop antibodies against the IE surface (Bull et al. 2005a; Rottmann et al. 2006; Warimwe et al. 2009, 2012) (see Table 2). In contrast, the expression of group C var genes tends, at least in children from Papua New Guinea, to be differentially elevated in children with asymptomatic infections (Kaestli et al. 2006; Falk et al. 2009).

This antigenic separation between group $\mathrm{A}$ and non-group A PfEMP1 reflects a functional 


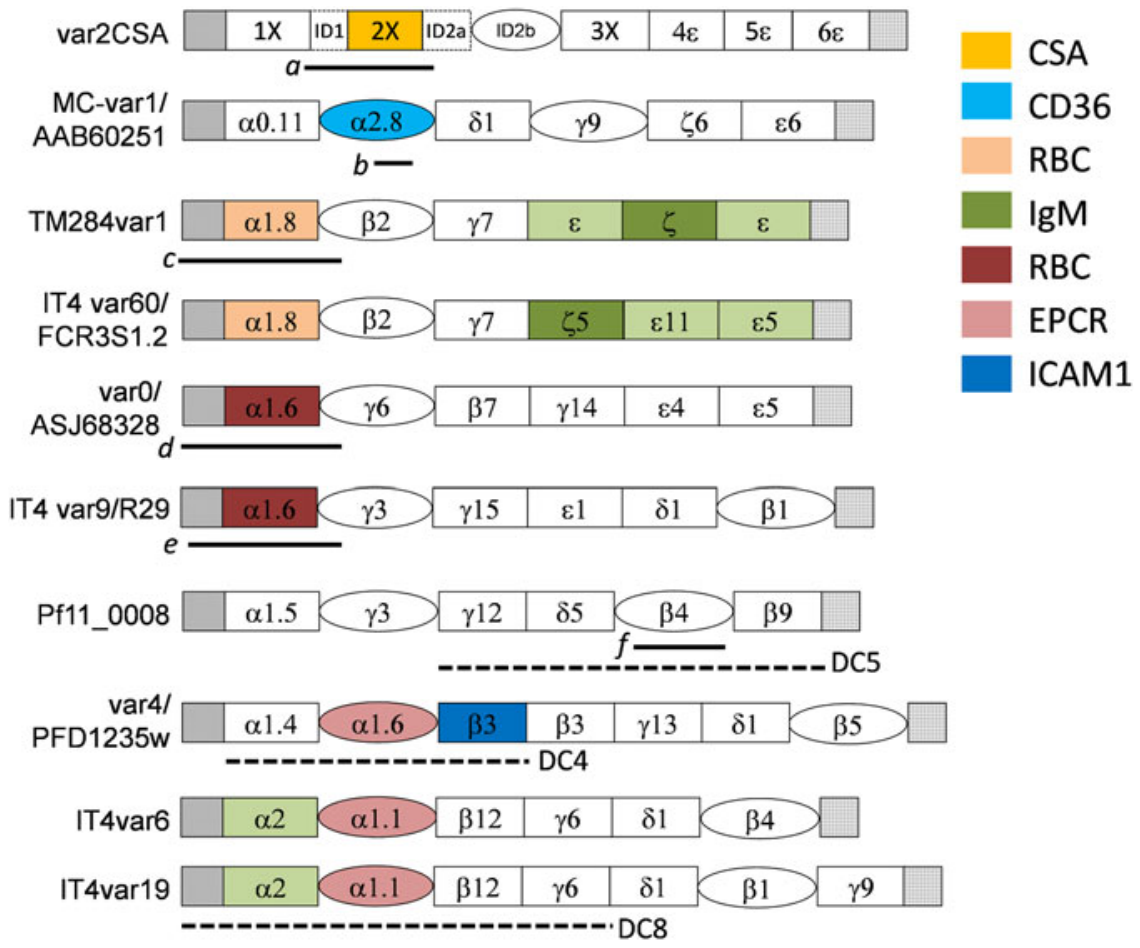

Fig. 2. The structures of some notable PfEMP1 variants. Duffy-binding domains (DBL) are shown as rectangles and cysteine-rich interdomain regions (CIDR) and the CIDR-like domain of var2CSA are shown as ovals, N-terminal segment and acidic terminal segment (ATS) sequences are shown as hatched and stippled squares, respectively. ID2a and ID2b are interdomain regions within var2CSA that from part of the DBL2X CSA-binding domain (Clausen et al. 2012). Cytoadhesion phenotypes associated with specific domains are shown as colours. Recombinant proteins derived from these PfEMP1 are shown as black horizontal lines under the region of the molecules from which they were derived a, b, c, d, e, f. Domain cassettes are shown as horizontal dashed lines: a, the Id1-DBL2X region can stimulate antibodies in mice that inhibit CSA binding (Bordbar et al. 2012); b, The r179 region of CD36-binding CIDR from the Malayan Camp line used by Baruch et al. (1997) to induce homologous protection in Aotus monkeys; c, the region of the IgM binding, rosette mediating TM284var1 used by Ghumra et al. (2012) to induce cross-reactive, opsonizing antibodies in rabbits; IT4var60 was found to be the rosette mediating var in the well-studied cell line FCR3S1·2 (Albrecht et al. 2011); d,e, constructs from non-IgM-binding, rosette-mediating PfEMP1 found to induce non-cross-reactive, rosette-inhibiting antibodies (Vigan-Womas et al. 2011); (Ghumra et al. 2012); The R29 line was recently found to simultaneously form rosettes and bind to human brain endothelial cells (Adams et al. 2014); f, naturally acquired antibodies to the DBL $\beta 4$ domain of pf11_0008 were associated with protection from future malaria in a longitudinal study (Magistrado et al. 2007). A PECAM1-binding domain cassette (DC5) was subsequently identified within this gene (Berger et al. 2013). Also shown are DCs, DC4 found to bind ICAM1 (Bengtsson et al. 2013), identified within var4 previously found to be dominantly expressed in parasites selected for binding to antibodies from semi-immune children (Jensen et al. 2004). Note the additional presence of a CIDR $\alpha 1.6$ within var4, shown to bind to EPCR by Lau et al. (2015) but not by Turner et al. (2013). IT4var6 and IT4var19 were two genes selected for binding to cells lines derived from human brain endothelial cells (Avril et al. 2012; Claessens et al.2012), within which the DC8 and the EPCR-binding CIDRa1·1 domain was identified (Turner et al. 2013).

difference between these two broad classes. Recombinant CIDR domains from the 'head structure' (i.e. the first DBL and CIDR domain) of non-group A PfEMP1 molecules usually bind to CD36, while those from group A PfEMP1 do not (Robinson et al. 2003; Janes et al. 2011). Recently, the phenomenon of mitotic recombination that would lead to immense additional PfEMP1 diversity appears to be restricted to non-group A PfEMP1 (Claessens et al. 2014). Together these observations are consistent with the idea of a trade-off between function and antigenic novelty shaping the genomic organization of the var gene family.
Exceptions to the molecular 'rules' may enable parasites to evade antibodies, prolong infections and cause severe malaria

For the sake of clarity, we have greatly simplified the distinction made above between the three classes of PfEMP1 types A, B and C. There are clear exceptions to these classifications and these exceptions to the norm may be of importance to our understanding of how these molecules evade antibodies. A transitional group between A and B PfEMP1 genes (B/ A) exist that have upsB promotors but are otherwise like group A genes (Lavstsen et al. 2003) and are 
Table 1. Immunological studies on PfEMP1 domains

\begin{tabular}{|c|c|c|c|c|c|c|c|c|c|c|c|c|c|}
\hline $\mathrm{DC}$ & Key domains & $\mathrm{SD}$ & $\mathrm{HB}$ & Motif & var & Adhesion & SM & $\begin{array}{l}\mathrm{C} / \mathrm{R} \\
\mathrm{Ab}\end{array}$ & $\begin{array}{l}\mathrm{P} . \\
\text { reich. }\end{array}$ & Antibodies & Surface & Protection & References \\
\hline DC11 & $\begin{array}{l}\text { NTS-DBL } \alpha 1 \cdot 8 / \\
\text { DBL } \zeta\end{array}$ & & & & & $\begin{array}{l}\text { Rosetting/ } \\
\text { IgM }\end{array}$ & & Yes & & Rabbits & Yes & Opsonization & [1] \\
\hline DC16 & $\begin{array}{l}\text { NTS-DBL } \alpha 1 \cdot 5 / \\
\text { DBL } \zeta\end{array}$ & & & & HB3VAR06 & $\begin{array}{l}\text { Rosetting/ } \\
\text { IgM }\end{array}$ & & Yes & & Rabbits & Yes & Opsonization & {$[1,2]$} \\
\hline DC5 & & & & & Pf11_0008 & PECAM & & No & Yes & Rat & Yes & Longitudinal & [3] \\
\hline DC4 & $\begin{array}{l}\text { CIDR } \alpha 1 \cdot 6 / D B L \beta 3- \\
\text { D4 }\end{array}$ & & & & var4 & $\begin{array}{l}\text { ICAM1/ } \\
\text { EPCR }\end{array}$ & Yes & Yes & Yes & Rat/human & Yes & IE adhesion & {$[4-7]$} \\
\hline DC13 & $\operatorname{CIDR} \alpha 1 \cdot 4$ & & & & & EPCR & Yes & Yes & & Human & Yes & & [8-10] \\
\hline \multirow[t]{13}{*}{ DC8 } & $\operatorname{CIDR} \alpha 1 \cdot 1$ & & & & IT4var19 & EPCR & Yes & Yes & & Human & Yes & & [8-11] \\
\hline & $\mathrm{CIDR} \alpha 1 \cdot 1$ & & & & & EPCR & & Yes & & Human & Yes & & {$[6,11]$} \\
\hline & $\mathrm{CIDR} \alpha 1 \cdot 4$ & & & & & EPCR & & Yes & & Human & Yes & & {$[6,11]$} \\
\hline & $\mathrm{CIDR} \alpha 1 \cdot 5$ & & & & & EPCR & & Yes & & Human & Yes & & [6] \\
\hline & $\mathrm{CIDR} \alpha 1 \cdot 8$ & & & & & EPCR & & Yes & & Human & Yes & & [6] \\
\hline & $\operatorname{CIDR} \alpha 2.8$ & & & & MC-var1 & CD36 & & Yes & & Aotus & No & Vaccination & [12] \\
\hline & CIDR $\beta 4$ & & & & Pf11_0008 & & & Yes & & Human & Yes & Longitudinal & [13] \\
\hline & NTS-DBL $\alpha 1 \cdot 6$ & 1,2 & & & $\operatorname{varO}$ & Rosetting & & No & & Human/mice & Yes & & {$[14,15]$} \\
\hline & NTS-DBL $\alpha 1 \cdot 8$ & 3 & & & IT4var60 & Rosetting & & Yes & & Mouse & Yes & Anti-roset & [16] \\
\hline & NTS-DBL $\alpha 1 \cdot 8$ & 1,2 & & & IT4var60 & & & Yes & & Human & & Anti-roset & [17] \\
\hline & NTS-DBL $\alpha 1 \cdot 8$ & $2-3$ & $\sim 2$ & DYVPQ(F/Y)LR & & & & Yes & & Human & & Anti-roset & {$[17]$} \\
\hline & NTS-DBL $\alpha 1 \cdot 8$ & 2 & 5 & $\begin{array}{l}\text { RDSM } \\
\text { (ALNRKE) }\end{array}$ & & & $\mathrm{RD}$ & Yes & & $\begin{array}{l}\text { Human/rat/ } \\
\text { rabbit }\end{array}$ & Yes & & {$[18,19]$} \\
\hline & & 1 & 4 & GACxPxRRxxLC & & C32 cells & & Yes & & Aotus & Yes & Vaccination & {$[20]$} \\
\hline
\end{tabular}

$\mathrm{DC}$, domain cassette; SD, sub-domain; HB, homology block; var, commonly used model var; $\mathrm{SM}$, association between expression and disease severity; $\mathrm{C} / \mathrm{R}$ Ab, Whether crossreactive antibodies have been detected; $P$. reich., identification of structure in Plasmodium reichenowi; antibodies, source of antibodies used; protection, the method used to demonstrate that antibodies are protective; longitudinal, longitudinal cohort studies of human populations; adhesion, reversal of infected erythrocyte adhesion; vaccination, protection demonstrated by vaccinating animals; anti-roset, rosette disruption by antibodies. RD, malaria with respiratory distress.

References: 1. Ghumra et al. (2012); 2. Stevenson et al. (2014); 3. Berger et al. (2013); 4. Jensen et al. (2004); 5. Bengtsson et al. (2013); 6. Lau et al. (2015); 7. Janes et al. (2011); 8. Avril et al. (2012); 9. Claessens et al. (2012); 10. Lavstsen et al. (2012); 11. Turner et al. (2013); 12. Gamain et al. (2001); 13. Magistrado et al. (2007); 14. Vigan-Womas et al. (2011); 15.

Vigan-Womas et al. (2012); 16. Angeletti et al. (2012); 17. Albrecht et al. (2014); 18. Normark et al. (2007); 19. Blomqvist et al. (2013); 20. Patarroyo et al. (2014). 
Table 2. A summary of PfEMP1 expression studies in clinical parasite isolates

\begin{tabular}{|c|c|c|c|c|c|c|c|c|c|c|c|c|c|c|c|c|c|c|c|c|c|c|c|c|c|c|c|c|c|c|c|}
\hline \multirow[b]{2}{*}{ Location } & \multirow[b]{2}{*}{ References } & \multirow[b]{2}{*}{ Patients } & \multirow[b]{2}{*}{ Method } & \multicolumn{7}{|c|}{ Disease severity } & \multicolumn{7}{|c|}{ Asymptomatic } & \multicolumn{7}{|l|}{ Age } & \multicolumn{7}{|c|}{ Antibodies } \\
\hline & & & & cys2 & $\mathrm{A}$ & B & $\mathrm{C}$ & 8 & 13 & $\mathrm{H}$ & cys 2 & $\mathrm{~A}$ & $\mathrm{~B}$ & $\mathrm{C}$ & 8 & 13 & $\mathrm{H}$ & cys2 & $\mathrm{A}$ & $\mathrm{B}$ & $\mathrm{C}$ & 8 & 13 & $\mathrm{H}$ & cys2 & $\mathrm{A}$ & $\mathrm{B}$ & $\mathrm{C}$ & 8 & 13 & $\mathrm{H}$ \\
\hline Brazil & {$[1]$} & Adults & DBL $\alpha$ tag & + & & & & & & & & & & & & & & & & & & & & & & & & & & & \\
\hline PNG & {$[2]$} & Children & qPCR & & 0 & 0 & 0 & & & & & 0 & - & + & & & & & & & & & & & & & & & & & \\
\hline PNG & [3] & Children & DBL $\alpha$ tag & 0 & 0 & 0 & 0 & & & & - & - & 0 & + & & & & 0 & 0 & 0 & + & & & & & & & & & & \\
\hline Kenva & {$[4]$} & Children & $\mathrm{DBL} \alpha$ tag & 0 & & & & & & & & & & & & & & 0 & & & & & & 0 & _- & & & & & & + \\
\hline Kenya & {$[5-7]$} & Children & $\mathrm{DBL} \alpha$ tag & + & + & & & & & 0 & 0 & 0 & & & & & + & - & - & & & & & 0 & - & - & & & & & + \\
\hline Tanzania & {$[8]$} & Children & qPCR & & + & + & 0 & & & & & - & - & 0 & & & & & - & 0 & 0 & & & & & & & & & & \\
\hline Tanzania & [9] & Children & qPCR & & + & 0 & & + & + & & & & & & & & & & & & & & & & & & & & & & \\
\hline Malawi & [10] & Children & $\mathrm{qPCR}$ & & + & - & 0 & & & & & & & & & & & & & & & & & & & & & & & & \\
\hline Uganda & {$[11]$} & Children & DBL $\alpha$ tag & 0 & & & & & & & & & & & & & & & & & & & & & & & & & & & \\
\hline Mali & [12] & Children & $\mathrm{DBL} \bar{\alpha}$ tag & + & & & & & & & & & & & & & & & & & & & & & & & & & & & \\
\hline Gabon & [13] & Children & qPCR & & - & + & + & & & & & & & & & & & & & & & & & & & & & & & & \\
\hline Gambia & {$[14]$} & Children & qPCR & & + & + & 0 & & & & & & & & & & & & & & & & & & & & & & & & \\
\hline Benin & {$[15]$} & Children & MS & & & & & + & & & & & & & & & & & & & & & & & & & & & & & \\
\hline Cameroon & {$[16]$} & Children & qPCR, MA & & 0 & 0 & 0 & + & + & & & - & - & 0 & 0 & 0 & & & & & & & & & & & & & & & \\
\hline
\end{tabular}

Positive and negative associations are shown as + and - symbol, respectively, lack of association is shown as 0 , blank means that the comparison was not done. Four levels of immunity are described: Disease severity refers to comparisons between severe and mild malaria, Asymptomatic refers to comparisons between asymptomatic and symptomatic infection; age refers to whether there was an association with higher age of the parasite donor at the time of infection; antibodies asks whether there was an association between var expression and levels of antibodies to infected erythrocytes. Var expression is described as A, Group A; B, group B; C, group C; 8, DC8; 13, DC13; H, Homogenetiy of the var expression profile i.e. the extent to which a single variant dominates. Methods: DBL $\alpha$ tag, an expressed sequence tag approach using cloned and sequenced, PCR amplified tags from the DBL $\alpha$ domain; qPCR, quantitative PCR using domain specific primers; MS, Mass spectrometry; MA, microarray.

References for each study are coded as follows: 1. Kirchgatter and Portillo Hdel (2002); 2. Kaestli et al. (2006); 3. Falk et al. (2009); 4. Bull et al. (2005a); 5. Warimwe et al. (2009); 6. Warimwe et al. (2012); 7. Warimwe et al. (2013); 8. Rottmann et al. (2006); 9. Lavstsen et al. (2012); 10. Tembo et al. (2014); 11. Normark et al. (2007); 12. Kyriacou et al. (2006); 13. Kalmbach et al. (2010); 14. Merrick et al. (2012); 15. Bertin et al. (2013); 16. Almelli et al. (2014). 
predicted not to bind CD36 (Robinson et al. 2003). Similarly transitional genes between groups B \& C (B/C) are common (Lavstsen et al. 2003). The existence of transitional groups indicates that the three classes of genes, cannot be considered as genetically distinct families of molecules.

To refine our understanding of var gene organization, Rask et al. (2010) developed a system of classification that works from the level of individual homology blocks and domain subclasses to define common structures within var genes independent of their upstream promotors. This has greatly expanded our ability to describe similarity and differences between PfEMP1 molecules. The most immediately useful idea has been that of the 'domain cassette' (DC). The most prominent DCs are shown in Fig. 2 and Table 1. Two DCs in particular, DC8 and DC13 are of interest because genes containing these were found to be enriched by selecting infected erythrocytes for in vitro adhesion to cell lines derived from human brain endothelial cells (Avril et al. 2012; Claessens et al. 2012) and are expressed in children with severe malaria (Lavstsen et al. 2012). Specific CIDR domain subclasses found within these DCs, instead of binding to CD36, are associated with binding to EPCR Adhesion to EPCR has been proposed to cause dysregulation of inflammation in the brain leading to cerebral malaria (Moxon et al. 2013; Turner et al. 2013). CIDR domains important to EPCR binding contain conserved epitopes close to the EPCRbinding site that are recognized by malaria-exposed children (Lau et al. 2015). In terms of vaccine development, these results are encouraging and further support the idea of broad functional specialization within PfEMP1 family.

Overall these studies demonstrate that modularity exists at various levels within the structure of PfEMP1 associated with childhood malaria: at the level of DCs, domain classes and homology blocks. This would potentially enable different functional and antigenic components to exist in varying contexts. Whether this modularity could delay responses to previously encountered functional domains through reassortment of T-cell and B-cell epitopes is yet to be explored. Buckee and Recker (2012) have suggested that the existence of large numbers of different functional domains on group A PfEMP1 could enable these molecules to support endothelial binding even after antibodies have reversed binding mediated by one or more of the domains. The observation of highly homogeneous expression of group A PfEMP1 in the presence of high levels of antibodies in both severe malaria (Warimwe et al. 2013) and asymptomatic infection (Warimwe et al. 2012) suggests that these antigenically more conserved variants can survive in individuals with high antibody responses, highlighting the need to fully understand how parasites evade antibodies. We have tended to emphasize the rapid acquisition of immunity to severe non-cerebral malaria (Gupta et al. 1999b) rather than the fact that cerebral malaria has a slightly later age prevalence than other forms of severe malaria (Greenwood et al. 1991; Marsh, 1992; Gupta et al. 1999a; Roca-Feltrer et al. 2010; Griffin et al. 2015) and may involve the ability of parasites to effectively escape from the existing antibody responses (see also Box 2).

\section{Immunological studies of PfEMP1 domains}

Five kinds of question need to be addressed in immunological and epidemiological studies to determine the extent to which different features of var genes are targets of naturally acquired immunity to malaria and/or potential vaccine candidates: (1) Are recombinant domains recognized broadly by naturally acquired antibodies or antibodies raised in animals? (2) Do antibodies raised in animals or adsorbed from human serum, bind to the surface of parasite infected erythrocytes, opsonise-infected erythrocytes or reverse cytoadhesion? (3) Is carriage of these antibodies associated with low frequency of future episodes of malaria or low severity of a current infection? (4) Is expression of the PfEMP1 feature by parasites in vivo negatively associated with host immunity measured as disease severity, IE antibodies carried at the time of infection or host age? (5) Are there conserved epitopes in PfEMP1 that can be targeted by antibodies? (6) Can antibodies be shown directly to protect against malaria?

Tables 1 and 2 together with Fig. 2 bring together some of the key information that has been gathered in relation to these questions. Considered alone these questions have important limitations. Question 1 does not distinguish between epitopes exposed by living or dead parasites. Question 3 carries the danger of confounding by cumulative exposure. Because of the diversity and immunogenicity of PfEMP1, recognition of various domains is likely to be excellent markers of past exposure, possibly better than the 'exposure' controls used.

Parasite expression levels in association with antibodies or age at the time of disease are likely to be a powerful approach to dissect specific components of the naturally acquired immune response. However, expression studies in parasites still rely heavily on indirect methods. Expression of DCs currently relies on $\mathrm{qPCR}$ using sets of primers that identify homology blocks within domains commonly encountered within specific DCs. It is important to note that this approach measures expression levels of specific DCs only indirectly and assumes that strong associations between homology blocks is maintained within the parasite population (Lavstsen et al. 2012). Further information is needed on the stability of DCs over time and geographical space. To understand the effect of 
antibody selection on various different sequence features within var genes we urgently need complete sequence information from expressed var genes from parasites infecting children with different levels of naturally acquired antibodies. This will help us to fully understand why children succumb to lifethreatening disease. To this end, a recent study has used mass spectrometry to identify sequence features related to DC8 in children with severe malaria (Bertin et al. 2013), but there are still only very few studies that have attempted to place var gene expression profiles at the time of severe malaria within the context of the immune response (Table 2).

\section{A summary of attempts to directly address the challenge of developing a PfEMP1-based vaccine to childhood malaria}

In this section, we will summarize the progress that has been made in direct attempts to address question 5 above and protect animals through vaccination with PfEMP1.

CD36-antibodies to CIDR. First attempts to raise cross-reactive antibodies to PfEMP1 focused on CD36-binding CIDR domains. The rationale for this was that the CIDR region, known to bind what was at the time the most prominent parasite receptor (CD36) was shown to be immunogenic and the target of antibodies that agglutinate parasites (Baruch et al. 1997). In the first study done through vaccination of Aotus monkeys with recombinant CD36-binding CIDR, there was cross-agglutination, and reactivity to recombinant CIDR, but this was not supported by surface labelling or reversal of CD36 binding (Gamain et al. 2001). Using the Aotus Monkey model, Baruch and colleagues subsequently demonstrated that immunization with a single short region of the CD36-binding region of a single CIDR [r179 from the 'Malayan Camp' laboratory parasite line (Baruch et al. 1997)] can immunize against infection with the homologous strain (Baruch et al. 2002). This seemed to suggest that 'determinant spreading' (Lehmann et al. 1993) was occurring and that immunization with a nonimmunodominant region boosts the development of cross-reactive antibodies. However, in this model in which monkeys were challenged directly with ring stage parasites, there is a clear first wave of infection that is dominated by a single variant, which may not model sporozoite challenge of humans (Wang et al. 2009). This may help explain why the vaccination did not protect against heterologous parasite isolates (Baruch et al. 2002). To favour the stimulation of cross-reactive antibodies, simultaneous vaccination of mice with three different proteins [MC CIDR1 (residues 1-267), FVO CIDR1 (residues 1-260) and A4tres CIDR1 (residues 1-262)] was used. This led to an increase in cross-recognition over separate vaccination (Gratepanche et al. 2003). However, such a regime did not protect Aotus from the virulent line FVO, despite some protection from anaemia (Makobongo et al. 2006).

Antibodies to DBLalpha. DBLalpha domains are present within all PfEMP1 variants associated with childhood malaria and are therefore an attractive domain to target in a vaccine. However, raising antibodies that recognize the surface of infected erythrocyte has been a challenge. Initial studies on immunization with Escherichia coli expressed DBLalpha region lead to antibodies that recognize conserved regions of recombinant proteins but that do not recognize the surface of the infected erythrocytes (Oguariri et al. 2003; Chen et al. 2004). This problem was overcome by immunization with mini-var Semliki forest virus constructs that are displayed on the surface of virus-infected cells. The effectiveness of antibodies in reversing rosetting was tested using antibodies against DBLalpha from FCR3S1·2var1 (Chen et al. 2004) and a rat lung in vivo sequestration model was used to test for reversal of sequestration. The in vivo model using $99 \mathrm{~m}$ technetium-labelled iRBC was also adapted for use in cynomolgus macaques and shown to be effective (Moll et al. 2007) and led to a $46 \%$ reduction in sequestration against the homologous isolate. However, the var gene used in these studies was subsequently shown not to be involved in rosetting (Albrecht et al. 2011) and the authors suggest that anti-rosetting activity was due to cross-reactivity.

The development of platforms for controlled human infection with malaria parasites are likely to allow rapid testing of vaccine candidates that has not been possible previously (Hodgson et al. 2014; Obiero et al. 2015).

\section{Global approaches to finding important protective epitopes on PfEMP1}

Using an entirely different approach, Blomqvist et al. (2013) used var gene expression data of parasites from Ugandan children to identify short stretches of PfEMP1 sequence that are associated with severe malaria (Normark et al. 2007). They raised antibodies to peptides based around these motifs. One of these peptides called RDSM (respiratory distress severe malaria) containing the ALNRKE motif and associated with respiratory distress, stimulated production of antibodies that crossreacted against several parasite lines including R29, whose expressed var gene (IT4 var9) contains the very similar AINRKE motif (Blomqvist et al. 2013). This region is in a relatively conserved part of the molecule in the same region as another 


\section{Box 1. Lessons from VAR2CSA.}

VAR2CSA presents us with what on the surface seemed like the best case scenario for developing a PfEMP1-based vaccine to targeting severe malaria. This has been more challenging perhaps than the expected but this should not be used as evidence that a vaccine based on other, more variable PfEMP1 involved in childhood malaria will be substantially more difficult to achieve.

The reason is that, unlike PfEMP1 associated with childhood malaria, VAR2CSA forms a compact structure, possibly due to the nature of the molecules to which it binds and the immunogenicity of the entire molecule is very different from the individual domains (Higgins and Carrington, 2014). This difference with other PfEMP1 is consistent with the fact that var2CSA is not genetically connected to the network of gene conversion events that occur between other var genes. If all var genes had compact structures these would be disrupted each time the genes recombined with other var genes. A modular structure is likely to be more robust to their mode of variation through recombination.

One specific challenge in the case of VAR2CSA is that naturally acquired immune responses tends to target regions DBL3X and DBL5e that are masked by their ability to bind non-specifically to IgM (Barfod et al. 2011). Though some PfEMP1 associated with childhood malaria bind non-specifically to $\operatorname{IgM}$, there is no evidence that they play a role in masking antigenic sites (Stevenson et al. 2014). Despite the non-specific binding to IgM (Lambert et al. 2014) have shown that naturally acquired opsonizing antibodies to infected erythrocytes expressing var2CSA can be inhibited by incubation with DBL2X, DBL3X or DBL5 $\varepsilon$ domains. The Nterminal NTS-DBL2X region of the molecule is a prime target because antibodies raised to this region effectively block adhesion to CSA (Bigey et al. 2011; Bordbar et al. 2012; NunesSilva et al. 2014). Doritchamou et al. (2013) have suggested that bivalent vaccine based on this region might be sufficient to provide broad protection. However, the DBL2X region alone can stimulate antibodies in mice that inhibit CSA binding (Bordbar et al. 2012) and structural studies have confirmed the location of the CSAbinding region within this domain (Clausen et al. 2012).

There appear to be fitness differences in naturally occurring var2CSA. Specific var2CSA sequences appear to be associated with high parasitaemia infections. This may suggest evolution of sequences to evade host antibodies, or that some sequences bind more strongly to chondroitin sulphate A (Rovira-Vallbona et al. 2013).

peptide from var2CSA that is associated with changes in sequence expression between primigravid and multigravid women (Dahlback et al. 2006).

Directing response to the conserved regions. As is the case with other highly diverse pathogens naturally acquired immune responses are most frequently directed towards the diverse immunodominant regions despite rare individuals who make substantial responses to conserved regions (Rathore et al. 2014). In HIV, researchers are trying to tackle this problem by directing the immune response to the most conserved regions of the surface antigens.

\section{Box 2. The link between virulence and transmission.}

Why are some PfEMP1 variants associated with more virulence than others? One suggestion from evolution of virulence theory, is that a trade-off exists between parasite virulence and effective transmission (Mackinnon and Read, 2004), i.e. that some level of virulence is required for competitive transmission to new hosts. For this reason, Hayward et al. (1999) attempted to demonstrate a close mechanistic link by demonstrating what appeared to be normal expression of CD36-binding PfEMP1 on early gametocytes. However, more recent data suggest that the link between the PfEMP1 expression and transmission is indirect since early gametocytes have a very different programme of PfEMP1 expression (Alano, 2014; Ankarklev et al. 2014). Recent articles have re-emphasized the link between virulence and transmissibility by demonstrating an increase in both broad var gene expression and sexual commitment in parasites carrying deletions for key epigenetic regulator genes PfHP1 (Coleman et al. 2014) and PfHDA2 (Brancucci et al. 2014a). However, it is important to distinguish clearly between mechanistic and evolutionary links between virulence and transmissibility. The PfAP2-G gene recently found to be the gene responsible for immediate control of sexual commitment is flanked by insulator-like pairing elements that are also found in var genes, raising the possibility that sexual commitment and var gene expression are under common control to ensure their expression is mutually exclusive (Kafsack et al. 2014). 
This they do by bringing together artificially the conserved regions of antigens into one composite antigen (Hanke, 2014). A similar approach has been explored for PfEMP1 by Patarroyo et al. (2014) who have initiated a high-throughput approach to screening 15-20aa long peptides for host cell binding [high activity binding peptides (HABPs)], immunogenicity and protective efficacy in Aotus. Their approach involves modifications of otherwise non-immunogenic regions within a single var gene (var2CSA from Dd2) to convert them into immunogenic peptides [modified HABPs (mHABPs)]. The most promising peptides are both located within homology block 4 (Rask et al. 2010) and contain the GACxPxRRxxLC canonical motif (Patarroyo et al. 2014).

\section{Future directions}

There have been some exciting recent developments in our understanding of the PfEMP1 family of surface antigens, but there are clearly challenges ahead.

Despite the plausible mechanism that would explain the pathology of cerebral malaria (Taylor et al. 2013) it is still unclear whether EPCR is a common receptor for parasites since only a relatively small number of clinical parasite isolates have so far been tested. A recent paper by Esser et al. (2014) suggests the existence of a large number of possible novel host receptors for PfEMP1; however, it is not clear if any of these could sustain an infection at high parasitaemia.

Two recent reports suggest that on the one hand var expression may be under some level of global control (Merrick et al. 2012) and on the other hand, that two other gene families may be able to support sequestration (Niang et al. 2014; Goel et al. 2015). PfEMP1 appears also to be partially controlled at the translational level (Brancucci et al. 2014b). This raises the possibility that the parasite could diversify both the type and total amount of variant antigen expressed on the infected erythrocyte surface.

The important question here is whether the level of sequestration supported by STEVOR and RIFINs in the absence of PfEMP1 could support parasite loads associated with severe malaria. Though knockdowns of var have an important effect on the antigenic properties of laboratory isolates (Chan et al. 2012), they may not fully model the behaviour of non-PfEMP1 VSA in vivo. Warimwe et al. (2012) observed an association between respiratory distress and rosetting in Kenya. Despite a strong overall association between rosetting and the expression of group $\mathrm{A}$ var genes, the observed association was independent of group A-like var gene expression or any other subgroup of var genes that could be identified. One possible interpretation of this is that the association between rosetting and respiratory distress was driven by a subset of parasites for which rosetting is mediated through RIFINs or STEVOR. This highlights the need for full sequence information of VSA expressed under different levels of naturally acquired immunity.

Future research on developing interventions based on PfEMP1 needs to continue to refine definitions of different cytoadhesive phenotypes at the molecular level. Various terms such as 'rosetting', 'VSA ${ }_{\mathrm{SM}}$ ', 'group A PfEMP1', 'DC8', in the same way as clinical definitions such as 'cerebral malaria' (Taylor et al. 2004), are essential for generating hypotheses, but what they describe are potentially heterogeneous. More studies are still needed to directly link structure, cytoadhesive function and antigenicity with naturally acquired immunity to clearly defined malarial disease.

\section{ACKNOWLEDGEMENT}

This paper was published by the permission of the Director of the Kenya Medical Research Institute.

\section{F INANCIAL SUPPORT}

A.A. was supported by the Wellcome Trust Training grant in Public Health and Tropical Medicine (grant no. 103956) and a Wellcome Trust Strategic Award (grant no. 084538).

\section{REFERENCES}

Adams, Y., Kuhnrae, P., Higgins, M. K., Ghumra, A. and Rowe, J. A. (2014). Rosetting Plasmodium falciparum-infected erythrocytes bind to human brain microvascular endothelial cells in vitro, demonstrating a dual adhesion phenotype mediated by distinct $P$. falciparum erythrocyte membrane protein 1 domains. Infection and Immunity 82, 949-959.

Aguiar, J.C., Albrecht, G. R., Cegielski, P., Greenwood, B. M., Jensen, J. B., Lallinger, G., Martinez, A., McGregor, I. A., Minjas, J. N., Neequaye, J., Patarroyo, M. E., Sherwood, J. A. and Howard, R. J. (1992). Agglutination of Plasmodium falciparum-infected erythrocytes from east and west African isolates by human sera from distant geographical regions. American Fournal of Tropical Medicine and Hygiene 47, 621-632.

Alano, P. (2014). The sound of sexual commitment breaks the silencing of malaria parasites. Trends in Parasitology 30, 509-510.

Albrecht, L., Moll, K., Blomqvist, K., Normark, J., Chen, Q. and Wahlgren, M. (2011). var gene transcription and PfEMP1 expression in the rosetting and cytoadhesive Plasmodium falciparum clone FCR3S1.2. Malaria Fournal 10, 17.

Albrecht, L., Angeletti, D., Moll, K., Blomqvist, K., Valentini, D., D'Alexandri, F.L., Maurer, M. and Wahlgren, M. (2014). B-Cell Epitopes in NTS-DBL1alpha of PfEMP1 Recognized by Human Antibodies in Rosetting Plasmodium falciparum. PLoS ONE 9, e113248. Almelli, T., Nuel, G., Bischoff, E., Aubouy, A., Elati, M., Wang, C. W., Dillies, M.A., Coppee, J.Y., Ayissi, G. N., Basco, L. K., Rogier, C., Ndam, N. T., Deloron, P. and Tahar, R. (2014). Differences in gene transcriptomic pattern of Plasmodium falciparum in children with cerebral malaria and asymptomatic carriers. PLoS ONE $\mathbf{9}$, e114401.

Angeletti, D., Albrecht, L., Blomqvist, K., Quintana Mdel, P., Akhter, T., Bachle, S. M., Sawyer, A., Sandalova, T., Achour, A., Wahlgren, M. and Moll, K. (2012). Plasmodium falciparum rosetting epitopes converge in the SD3-loop of PfEMP1-DBL1alpha. PLoS ONE 7, e50758.

Ankarklev, J., Brancucci, N. M., Goldowitz, I., Mantel, P. Y. and Marti, M. (2014). Sex: how malaria parasites get turned on. Current Biology 24, R368-R370. 
Avril, M., Tripathi, A. K., Brazier, A. J., Andisi, C., Janes, J. H., Soma, V. L., Sullivan, D. J., Bull, P. C., Stins, M. F. and Smith, J. D. (2012). A restricted subset of var genes mediates adherence of Plasmodium falciparum-infected erythrocytes to brain endothelial cells. Proceedings of the National Academy of Sciences of the United States of America 109, E1782-E1790.

Barfod, L., Dalgaard, M. B., Pleman, S. T., Ofori, M. F., Pleass, R. J. and Hviid, L. (2011). Evasion of immunity to Plasmodium falciparum malaria by IgM masking of protective IgG epitopes in infected erythrocyte surface-exposed PfEMP1. Proceedings of the National Academy of Sciences of the United States of America 108, 12485-12490.

Barnwell, J. W., Howard, R. J., Coon, H. G. and Miller, L. H. (1983). Splenic requirement for antigenic variation and expession of the variant antigen on the erythrocyte membrane in cloned Plasmodium knowlesi malaria. Infection and Immunity 40, 985-994.

Barragan, A., Kremsner, P. G., Weiss, W., Wahlgren, M. and Carlson, J. (1998). Age-related buildup of humoral immunity against epitopes for rosette formation and agglutination in African areas of malaria endemicity. Infection and Immunity 66, 4783-4787.

Barry, A. E., Leliwa-Sytek, A., Tavul, L., Imrie, H., Migot-Nabias, F., Brown, S. M., McVean, G. A. and Day, K. P. (2007). Population genomics of the immune evasion (var) genes of Plasmodium falciparum. PLoS Pathogens 3, e34.

Baruch, D. I., Pasloske, B. L., Singh, H. B., Bi, X., Ma, X.C., Feldman, M., Taraschi, T. F. and Howard, R. J. (1995). Cloning the Plasmodium falciparum gene encoding PfEMP1, a malarial variant antigen and adherence receptor on the surface of parasitized human erythrocytes. Cell 82, 77-87.

Baruch, D. I., Ma, X. C., Singh, H. B., Bi, X., Pasloske, B. L. and Howard, R. J. (1997). Identification of a region of PfEMP1 that mediates adherence of Plasmodium falciparum infected erythrocytes to CD36: conserved function with variant sequence. Blood 90, 37663775

Baruch, D. I., Gamain, B., Barnwell, J.W., Sullivan, J.S., Stowers, A., Galland, G. G., Miller, L. H. and Collins, W. E. (2002). Immunization of Aotus monkeys with a functional domain of the Plasmodium falciparum variant antigen induces protection against a lethal parasite line. Proceedings of the National Academy of Sciences of the United States of America 99, 3860-3865.

Beeson, J. G., Brown, G. V., Molyneux, M. E., Mhango, C., Dzinjalamala, F. and Rogerson, S. J. (1999). Plasmodium falciparum isolates from infected pregnant women and children are associated with distinct adhesive and antigenic properties. Fournal of Infectious Diseases $\mathbf{1 8 0}$, 464-472.

Bengtsson, A., Joergensen, L., Rask, T. S., Olsen, R. W., Andersen, M. A., Turner, L., Theander, T. G., Hviid, L., Higgins, M. K., Craig, A., Brown, A. and Jensen, A. T. (2013). A novel domain cassette identifies Plasmodium falciparum PfEMP1 proteins binding ICAM-1 and is a target of cross-reactive, adhesion-inhibitory antibodies. Fournal of Immunology 190, 240-249.

Berger, S. S., Turner, L., Wang, C. W., Petersen, J.E., Kraft, M., Lusingu, J.P., Mmbando, B., Marquard, A.M., Bengtsson, D. B., Hviid, L., Nielsen, M. A., Theander, T. G. and Lavstsen, T. (2013). Plasmodium falciparum expressing domain cassette 5 type PfEMP1 (DC5-PfEMP1) bind PECAM1. PLoS ONE 8, e69117.

Bertin, G. I., Lavstsen, T., Guillonneau, F., Doritchamou, J., Wang, C. W., Jespersen, J. S., Ezimegnon, S., Fievet, N., Alao, M. J., Lalya, F., Massougbodji, A., Ndam, N. T., Theander, T. G. and Deloron, P. (2013). Expression of the domain cassette 8 Plasmodium falciparum erythrocyte membrane protein 1 is associated with cerebral malaria in Benin. PLoS ONE 8, e68368.

Bigey, P., Gnidehou, S., Doritchamou, J., Quiviger, M., Viwami, F., Couturier, A., Salanti, A., Nielsen, M. A., Scherman, D., Deloron, P. and Tuikue Ndam, N. (2011). The NTS-DBL2X region of VAR2CSA induces cross-reactive antibodies that inhibit adhesion of several Plasmodium falciparum isolates to chondroitin sulfate A. Fournal of Infectious Diseases 204, 1125-1133.

Biggs, B. A., Gooze, L., Wycherley, K., Wollish, W., Southwell, B., Leech, J.H. and Brown, G.V. (1991). Antigenic variation in Plasmodium falciparum. Proceedings of the National Academy of Sciences of the United States of America 88, 9171-9174.

Blomqvist, K., Albrecht, L., Quintana Mdel, P., Angeletti, D., Joannin, N., Chene, A., Moll, K. and Wahlgren, M. (2013). A sequence in subdomain 2 of DBL1alpha of Plasmodium falciparum erythrocyte membrane protein 1 induces strain transcending antibodies. PLoS ONE $\mathbf{8}$ e52679.

Bordbar, B., Tuikue-Ndam, N., Bigey, P., Doritchamou, J., Scherman, D. and Deloron, P. (2012). Identification of Id1-DBL2X of VAR2CSA as a key domain inducing highly inhibitory and cross-reactive antibodies. Vaccine 30, 1343-1348.

Brancucci, N. M., Bertschi, N.L., Zhu, L., Niederwieser, I., Chin, W. H., Wampfler, R., Freymond, C., Rottmann, M., Felger, I., Bozdech, Z. and Voss, T.S. (2014a). Heterochromatin protein 1 secures survival and transmission of malaria parasites. Cell Host Microbe 16, 165-176.

Brancucci, N. M., Witmer, K., Schmid, C. and Voss, T. S. (2014b). A var gene upstream element controls protein synthesis at the level of translation initiation in Plasmodium falciparum. PLoS ONE 9, e100183.

Buckee, C. O. and Recker, M. (2012). Evolution of the multi-domain structures of virulence genes in the human malaria parasite, Plasmodium falciparum. PLoS Computational Biology 8, e1002451.

Bull, P. C., Lowe, B. S., Kortok, M., Molyneux, C. S., Newbold, C. I. and Marsh, K. (1998). Parasite antigens on the infected red cell surface are targets for naturally acquired immunity to malaria. Nature Medicine 4, 358-360.

Bull, P. C., Lowe, B. S., Kortok, M. and Marsh, K. (1999). Antibody recognition of Plasmodium falciparum erythrocyte surface antigens in Kenya: evidence for rare and prevalent variants. Infection and Immunity 67, 733-739.

Bull, P. C., Kortok, M., Kai, O., Ndungu, F., Ross, A., Lowe, B. S. Newbold, C. I. and Marsh, K. (2000). Plasmodium falciparum-infected erythrocytes: agglutination by diverse Kenyan plasma is associated with severe disease and young host age. Fournal of Infectious Diseases 182, $252-259$.

Bull, P. C., Lowe, B. S., Kaleli, N., Njuga, F., Kortok, M., Ross, A. Ndungu, F., Snow, R. W. and Marsh, K. (2002). Plasmodium falciparum infections are associated with agglutinating antibodies to parasite infected erythrocyte surface antigens among healthy Kenyan children. Fournal of Infectious Diseases 185, 1688-1691.

Bull, P. C., Berriman, M., Kyes, S., Quail, M. A., Hall, N., Kortok, M. M., Marsh, K. and Newbold, C. I. (2005a). Plasmodium falciparum variant surface antigen expression patterns during malaria. PLoS Pathogens 1, e26.

Bull, P. C., Pain, A., Ndungu, F. M., Kinyanjui, S. M., Roberts, D. J., Newbold, C. I. and Marsh, K. (2005b). Plasmodium falciparum antigenic variation: relationships between in-vivo selection, the acquired antibody response and disease severity. Fournal of Infectious Diseases 192, 1119-1126.

Bull, P.C., Buckee, C.O., Kyes, S., Kortok, M. M., Thathy, V., Guyah, B., Stoute, J. A., Newbold, C. I. and Marsh, K. (2008). Plasmodium falciparum antigenic variation. Mapping mosaic var gene sequences onto a network of shared, highly polymorphic sequence blocks. Molecular Microbiology 68, 1519-1534

Carlson, J., Helmby, H., Hill, A. V. S., Brewster, D., Greenwood, B. M. and Wahlgren, M. M. (1990). Human cerebral malaria: association with erythrocyte rosetting and lack of anti-rosetting antibodies. The Lancet 336, 1457-1460.

Cham, G. K., Turner, L., Lusingu, J., Vestergaard, L., Mmbando, B. P., Kurtis, J. D., Jensen, A.T., Salanti, A., Lavstsen, T. and Theander, T. G. (2009). Sequential, ordered acquisition of antibodies to Plasmodium falciparum erythrocyte membrane protein 1 domains. Fournal of Immunology 183, 3356-3363.

Cham, G. K., Turner, L., Kurtis, J. D., Mutabingwa, T., Fried, M., Jensen, A. T., Lavstsen, T., Hviid, L., Duffy, P. E. and Theander, T. G. (2010). Hierarchical, domain type-specific acquisition of antibodies to Plasmodium falciparum erythrocyte membrane protein 1 in Tanzanian children. Infection and Immunity 78, 4653-4659.

Chan, J. A., Howell, K. B., Reiling, L., Ataide, R., Mackintosh, C. L., Fowkes, F. J., Petter, M., Chesson, J. M., Langer, C., Warimwe, G. M., Duffy, M.F., Rogerson, S. J., Bull, P.C., Cowman, A.F., Marsh, K. and Beeson, J. G. (2012). Targets of antibodies against Plasmodium falciparum-infected erythrocytes in malaria immunity. Fournal of Clinical Investigation 122, 3227-3238.

Chan, J. A., Fowkes, F. J. and Beeson, J. G. (2014). Surface antigens of Plasmodium falciparum-infected erythrocytes as immune targets and malaria vaccine candidates. Cellular and Molecular Life Sciences $\mathbf{7 1}$ 3633-3657.

Chen, Q., Pettersson, F., Vogt, A. M., Schmidt, B., Ahuja, S., Liljestrom, P. and Wahlgren, M. (2004). Immunization with PfEMP1-DBL1alpha generates antibodies that disrupt rosettes and protect against the sequestration of Plasmodium falciparum-infected erythrocytes. Vaccine 22, 2701-2712.

Cheng, Q., Cloonan, N., Fischer, K., Thompson, J., Waine, G., Lanzer, M. and Saul, A. (1998). stevor and rif are Plasmodium falciparum multicopy gene families which potentially encode variant antigens. Molecular and Biochemical Parasitology 97, 161-176. 
Claessens, A., Adams, Y., Ghumra, A., Lindergard, G., Buchan, C. C., Andisi, C., Bull, P. C., Mok, S., Gupta, A.P. and Wang, C. W. (2012). A subset of group A-like var genes encodes the malaria parasite ligands for binding to human brain endothelial cells. Proceedings of the National Academy of Sciences of the United States of America 109, E1772-E1781

Claessens, A., Hamilton, W.L., Kekre, M., Otto, T.D., Faizullabhoy, A., Rayner, J. C. and Kwiatkowski, D. (2014). Generation of antigenic diversity in Plasmodium falciparum by structured rearrangement of var genes during mitosis. PLoS Genetics 10, e1004812.

Clausen, T. M., Christoffersen, S., Dahlback, M., Langkilde, A. E., Jensen, K. E., Resende, M., Agerbaek, M. O., Andersen, D., Berisha, B., Ditlev, S. B., Pinto, V. V., Nielsen, M. A., Theander, T. G., Larsen, S. and Salanti, A. (2012). Structural and functional insight into how the Plasmodium falciparum VAR2CSA protein mediates binding to chondroitin sulfate $\mathrm{A}$ in placental malaria. Fournal of Biological Chemistry 287, 23332-23345.

Coleman, B. I., Skillman, K. M., Jiang, R.H., Childs, L. M., Altenhofen, L. M., Ganter, M., Leung, Y., Goldowitz, I., Kafsack, B. F., Marti, M., Llinas, M., Buckee, C. O. and Duraisingh, M. T. (2014). A Plasmodium falciparum histone deacetylase regulates antigenic variation and gametocyte conversion. Cell Host Microbe 16, 177-186.

Dahlback, M., Rask, T.S., Andersen, P.H., Nielsen, M. A., Ndam, N. T., Resende, M., Turner, L., Deloron, P., Hviid, L., Lund, O., Pedersen, A. G., Theander, T. G. and Salanti, A. (2006). Epitope mapping and topographic analysis of VAR2CSA DBL3X involved in P. falciparum placental sequestration. PLoS Pathogens 2, e124.

de Boer, R. J. and Boerlijst, M. C. (1994). Diversity and virulence thresholds in AIDS. Proceedings of the National Academy of Sciences of the United States of America 91, 544-548.

Dodoo, D., Staalsoe, T., Giha, H., Kurtzhals, J. A., Akanmori, B. D., Koram, K., Dunyo, S., Nkrumah, F. K., Hviid, L. and Theander, T. G. (2001). Antibodies to variant antigens on the surfaces of infected erythrocytes are associated with protection from malaria in Ghanaian children. Infection and Immunity 69, 3713-3718.

Doritchamou, J., Bigey, P., Nielsen, M. A., Gnidehou, S., Ezinmegnon, S., Burgain, A., Massougbodji, A., Deloron, P., Salanti, A. and Ndam, N. T. (2013). Differential adhesion-inhibitory patterns of antibodies raised against two major variants of the NTSDBL2X region of VAR2CSA. Vaccine 31, 4516-4522.

Esser, C., Bachmann, A., Kuhn, D., Schuldt, K., Forster, B., Thiel, M., May, J., Koch-Nolte, F., Yanez-Mo, M., SanchezMadrid, F., Schinkel, A.H., Jalkanen, S., Craig, A. G., Bruchhaus, I. and Horstmann, R. D. (2014). Evidence of promiscuous endothelial binding by Plasmodium falciparum-infected erythrocytes. Cellular Microbiology 16, 701-708.

Falk, N., Kaestli, M., Qi, W., Ott, M., Baea, K., Cortes, A. and Beck, H. P. (2009). Analysis of Plasmodium falciparum var genes expressed in children from Papua New Guinea. Journal of Infectious Diseases 200, 347-356.

Fernandez, V., Hommel, M., Chen, Q., Hagblom, P. and Wahlgren, M. (1999). Small, clonally variant antigens expressed on the surface of the Plasmodium falciparum-infected erythrocyte are encoded by the rif gene family and are the target of human immune responses. Fournal of Experimental Medicine 190, 1393-1404.

Forsyth, K. P., Philip, G., Smith, T., Kum, E., Southwell, B. and Brown, G. V. (1989). Diversity of antigens expressed on the surface of erythrocytes infected with mature Plasmodium falciparum parasites in Papua New Guinea. American Fournal of Tropical Medicine and Hygiene 41, 259-265.

Frank, S. A. and Bush, R. M. (2007). Barriers to antigenic escape by pathogens: trade-off between reproductive rate and antigenic mutability. BMC Evolutionary Biology 7, 229

Gamain, B., Miller, L. H. and Baruch, D. I. (2001). The surface variant antigens of Plasmodium falciparum contain cross-reactive epitopes. Proceedings of the National Academy of Sciences of the United States of America 98, 2664-2669.

Gardner, M. J., Hall, N., Fung, E., White, O., Berriman, M., Hyman, R. W., Carlton, J. M., Pain, A., Nelson, K. E., Bowman, S., Paulsen, I. T., James, K., Eisen, J. A., Rutherford, K., Salzberg, S. L., Craig, A., Kyes, S., Chan, M.S., Nene, V., Shallom, S. J., Suh, B., Peterson, J., Angiuoli, S., Pertea, M., Allen, J., Selengut, J., Haft, D., Mather, M. W., Vaidya, A. B., Martin, D. M. et al. (2002). Genome sequence of the human malaria parasite Plasmodium falciparum. Nature 419, 498-511.

Ghumra, A., Semblat, J. P., McIntosh, R. S., Raza, A., Rasmussen, I. B., Braathen, R., Johansen, F. E., Sandlie, I., Mongini, P. K., Rowe, J
A. and Pleass, R. J. (2008). Identification of residues in the Cmu4 domain of polymeric IgM essential for interaction with Plasmodium falciparum erythrocyte membrane protein 1 (PfEMP1). Fournal of Immunology 181, 1988-2000.

Ghumra, A., Semblat, J.-P., Ataide, R., Kifude, C., Adams, Y. Claessens, A., Anong, D. N., Bull, P. C., Fennell, C. and Arman, M. (2012). Induction of strain-transcending antibodies against Group A PfEMP1 surface antigens from virulent malaria parasites. PLoS Pathogens 8, e1002665.

Giha, H. A., Staalsoe, T., Dodoo, D., Roper, C., Satti, G. M., Arnot, D. E., Hviid, L. and Theander, T. G. (2000). Antibodies to variable Plasmodium falciparum-infected erythrocyte surface antigens are associated with protection from novel malaria infections. Immunology Letters 71, 117-126.

Goel, S., Palmkvist, M., Moll, K., Joannin, N., Lara, P., Akhouri, R., Moradi, R., Ojemalm, K., Westman, M., Angeletti, D., Kjellin, H., Lehtio, J., Blixt, O., Idestrom, L., Gahmberg, C. G., Storry, J. R., Hult, A.K., Olsson, M.L., von Heijne, G., Nilsson, I. and Wahlgren, M. (2015). RIFINs are adhesins implicated in severe Plasmodium falciparum malaria. Nature Medicine 21, 314-317.

Goncalves, B.P., Huang, C.Y., Morrison, R., Holte, S. Kabyemela, E., Prevots, D. R., Fried, M. and Duffy, P. E. (2014) Parasite burden and severity of malaria in Tanzanian children. New England Fournal of Medicine 370, 1799-1808.

Gratepanche, S., Gamain, B., Smith, J. D., Robinson, B. A., Saul, A. and Miller, L. H. (2003). Induction of crossreactive antibodies against the Plasmodium falciparum variant protein. Proceedings of the National Academy of Sciences of the United States of America 100, 13007-13012. Greenwood, B., Marsh, K. and Snow, R. (1991). Why do some African Children develop severe malaria. Parasitology Today 7, 277-281. Griffin, J. T., Hollingsworth, T. D., Reyburn, H., Drakeley, C. J., Riley, E. M. and Ghani, A. C. (2015). Gradual acquisition of immunity to severe malaria with increasing exposure. Proceedings of the Royal Society of London Series B 282, 20142657.

Gupta, S., Snow, R. W., Donnelly, C. and Newbold, C. (1999a). Acquired immunity and postnatal clinical protection in childhood cerebral malaria. Proceedings of the Royal Society of London Series B 266, 33-38. Gupta, S., Snow, R. W., Donnelly, C. A., Marsh, K. and Newbold, C. $(1999 b)$. Immunity to non-cerebral severe malaria is acquired after one or two infections. Nature Medicine 5, 340-343.

Hanke, T. (2014). Conserved immunogens in prime-boost strategies for the next-generation HIV-1 vaccines. Expert Opinion on Biological Therapy 14, 601-616.

Hayward, R. E., Tiwari, B., Piper, K. P., Baruch, D. I. and Day, K. P. (1999). Virulence and transmission success of the malarial parasite Plasmodium falciparum. Proceedings of the National Academy of Sciences of the United States of America 96, 4563-4568.

Heddini, A., Pettersson, F., Kai, O., Shafi, J., Obiero, J., Chen, Q., Barragan, A., Wahlgren, M. and Marsh, K. (2001). Fresh isolates from children with severe Plasmodium falciparum malaria bind to multiple receptors. Infection and Immunity 69, 5849-5856.

Higgins, M. K. and Carrington, M. (2014). Sequence variation and structural conservation allows development of novel function and immune evasion in parasite surface protein families. Protein Science $\mathbf{2 3}$ 354-365.

Hodgson, S.H., Juma, E., Salim, A., Magiri, C., Kimani, D., Njenga, D., Muia, A., Cole, A. O., Ogwang, C., Awuondo, K. Lowe, B., Munene, M., Billingsley, P.F., James, E. R., Gunasekera, A., Sim, B.K., Njuguna, P., Rampling, T.W., Richman, A., Abebe, Y., Kamuyu, G., Muthui, M., Elias, S. C., Molyneux, S., Gerry, S., Macharia, A., Williams, T. N., Bull, P. C., Hill, A. V., Osier, F.H. et al. (2014). Evaluating controlled human malaria infection in Kenyan adults with varying degrees of prior exposure to Plasmodium falciparum using sporozoites administered by intramuscular injection. Frontiers in Microbiology 5, 686.

Iqbal, J., Perlmann, P. and Berzins, K. (1993). Serological diversity of antigens expressed on the surface of erythrocytes infected with Plasmodium falciparum. Transactions of the Royal Society of Tropical Medicine and Hygiene 87, 583-588.

Janes, J. H., Wang, C. P., Levin-Edens, E., Vigan-Womas, I., Guillotte, M., Melcher, M., Mercereau-Puijalon, O. and Smith, J. D. (2011). Investigating the host binding signature on the Plasmodium falciparum PfEMP1 protein family. PLoS Pathogens 7, e1002032.

Jensen, A. T., Magistrado, P., Sharp, S., Joergensen, L., Lavstsen, T., Chiucchiuini, A., Salanti, A., Vestergaard, L.S., Lusingu, J.P., Hermsen, R., Sauerwein, R., Christensen, J., Nielsen, M. A. Hviid, L., Sutherland, C., Staalsoe, T. and Theander, T. G. (2004). Plasmodium falciparum associated with severe childhood malaria 
preferentially expresses PfEMP1 encoded by group A var genes. Fournal of Experimental Medicine 199, 1179-1190.

Joergensen, L., Turner, L., Magistrado, P., Dahlback, M. A., Vestergaard, L.S., Lusingu, J.P., Lemnge, M., Salanti, A., Theander, T. G. and Jensen, A. T. (2006). Limited cross-reactivity among domains of the Plasmodium falciparum clone 3D7 erythrocyte membrane protein 1 family. Infection and Immunity 74, 6778-6784.

Joergensen, L., Vestergaard, L. S., Turner, L., Magistrado, P., Lusingu, J.P., Lemnge, M., Theander, T. G. and Jensen, A.T. (2007). 3D7-Derived Plasmodium falciparum erythrocyte membrane protein 1 is a frequent target of naturally acquired antibodies recognizing protein domains in a particular pattern independent of malaria transmission intensity. Fournal of Immunology 178, 428-435.

Kaestli, M., Cockburn, I. A., Cortes, A., Baea, K., Rowe, J. A. and Beck, H. P. (2006). Virulence of malaria is associated with differential expression of Plasmodium falciparum var gene subgroups in a case-control study. Fournal of Infectious Diseases 193, 1567-1574.

Kafsack, B. F., Rovira-Graells, N., Clark, T. G., Bancells, C., Crowley, V. M., Campino, S. G., Williams, A. E., Drought, L. G., Kwiatkowski, D. P., Baker, D. A., Cortes, A. and Llinas, M. (2014). A transcriptional switch underlies commitment to sexual development in malaria parasites. Nature 507, 248-252.

Kalmbach, Y., Rottmann, M., Kombila, M., Kremsner, P. G., Beck, H. P. and Kun, J. F. (2010). Differential var gene expression in children with malaria and antidromic effects on host gene expression. Fournal of Infectious Diseases 202, 313-317.

Karamanou, M., Liappas, I., Antoniou, C., Androutsos, G. and Lykouras, E. (2013). Julius Wagner-Jauregg (1857-1940): introducing fever therapy in the treatment of neurosyphilis. Psychiatriki 24, 208-212. Kinyanjui, S. M., Mwangi, T., Bull, P.C., Newbold, C. I. and Marsh, K. (2004). Protection against clinical malaria by heterologous immunoglobulin $\mathrm{G}$ antibodies against malaria-infected erythrocyte varian surface antigens requires interaction with asymptomatic infections. Fournal of Infectious Diseases 190, 1527-1533.

Kirchgatter, K. and Portillo Hdel, A. (2002). Association of severe noncerebral Plasmodium falciparum malaria in Brazil with expressed PfEMP1 DBL1 alpha sequences lacking cysteine residues. Molecular Medicine $\mathbf{8}$, 16-23.

Klein, J. and O'Huigin, C. (1994). MHC polymorphism and parasites. Philosophical Transactions of the Royal Society of London. Series B, Biological Sciences 346, 351-357; discussion 357-358.

Klein, M. M., Gittis, A. G., Su, H.P., Makobongo, M. O., Moore, J. M., Singh, S., Miller, L.H. and Garboczi, D. N. (2008). The cysteine-rich interdomain region from the highly variable plasmodium falciparum erythrocyte membrane protein-1 exhibits a conserved structure. PLoS Pathogens 4, e1000147.

Kraemer, S. M. and Smith, J. D. (2003). Evidence for the importance of genetic structuring to the structural and functional specialization of the Plasmodium falciparum var gene family. Molecular Microbiology 50, 15271538

Kraemer, S. M., Kyes, S. A., Aggarwal, G., Springer, A. L. Nelson, S. O., Christodoulou, Z., Smith, L. M., Wang, W., Levin, E., Newbold, C. I., Myler, P. J. and Smith, J. D. (2007). Patterns of gene recombination shape var gene repertoires in Plasmodium falciparum: comparisons of geographically diverse isolates. BMC Genomics $\mathbf{8}, 45$

Kyes, S. A., Rowe, J. A., Kriek, N. and Newbold, C. I. (1999). Rifins: a second family of clonally variant proteins expressed on the surface of red cells infected with Plasmodium falciparum. Proceedings of the National Academy of Sciences of the United States of America 96, 9333-9338.

Kyriacou, H. M., Stone, G. N., Challis, R. J., Raza, A., Lyke, K. E., Thera, M. A., Kone, A.K., Doumbo, O.K., Plowe, C. V. and Rowe, J. A. (2006). Differential var gene transcription in Plasmodium falciparum isolates from patients with cerebral malaria compared to hyperparasitaemia. Molecular and Biochemical Parasitology 150, 211-218.

Lambert, L. H., Bullock, J. L., Cook, S. T., Miura, K., Garboczi, D. N., Diakite, M., Fairhurst, R. M., Singh, K. and Long, C. A. (2014). Antigen reversal identifies targets of opsonizing IgGs against pregnancy-associated malaria. Infection and Immunity 82, 4842-4853.

Langhorne, J., Ndungu, F. M., Sponaas, A. M. and Marsh, K. (2008). Immunity to malaria: more questions than answers. Nature Immunology $\mathbf{9}$, 725-732.

Langreth, S. G. and Reese, R. T. (1979). Antigenicity of the infectederythrocyte and merozoite surfaces in Falciparum malaria. Fournal of Experimental Medicine 150, 1241-1254.

Lau, C. K., Turner, L., Jespersen, J.S., Lowe, E. D., Petersen, B., Wang, C. W., Petersen, J. E., Lusingu, J., Theander, T. G., Lavstsen, T. and Higgins, M. K. (2015). Structural conservation despite huge sequence diversity allows EPCR binding by the PfEMP1 family implicated in severe childhood malaria. Cell Host Microbe $\mathbf{1 7}$ 118-129.

Lavstsen, T., Salanti, A., Jensen, A. T., Arnot, D. E. and Theander, T. G. (2003). Sub-grouping of Plasmodium falciparum 3D7 var genes based on sequence analysis of coding and non-coding regions. Malaria fournal 2, 27. Lavstsen, T., Turner, L., Saguti, F., Magistrado, P., Rask, T.S., Jespersen, J.S., Wang, C.W., Berger, S. S., Baraka, V., Marquard, A. M., Seguin-Orlando, A., Willerslev, E., Gilbert, M. T., Lusingu, J. and Theander, T. G. (2012). Plasmodium falciparum erythrocyte membrane protein 1 domain cassettes 8 and 13 are associated with severe malaria in children. Proceedings of the National Academy of Sciences of the United States of America 109, E1791-E1800.

Lehmann, P. V., Sercarz, E. E., Forsthuber, T., Dayan, C. M. and Gammon, G. (1993). Determinant spreading and the dynamics of the autoimmune T-cell repertoire. Immunology Today 14, 203-208.

Mackinnon, M. J. and Read, A. F. (2004). Virulence in malaria: an evolutionary viewpoint. Philosophical Transactions of the Royal Society of London. Series B, Biological Sciences 359, 965-986.

Mackintosh, C. L., Mwangi, T., Kinyanjui, S. M., Mosobo, M., Pinches, R., Williams, T. N., Newbold, C. I. and Marsh, K. (2008). Failure to respond to the surface of Plasmodium falciparum infected erythrocytes predicts susceptibility to clinical malaria amongst African children. International Fournal of Parasitology 38, 1445-1454.

Magistrado, P. A., Lusingu, J., Vestergaard, L.S., Lemnge, M., Lavstsen, T., Turner, L., Hviid, L., Jensen, A. T. and Theander, T. G. (2007). Immunoglobulin $G$ antibody reactivity to a group A Plasmodium falciparum erythrocyte membrane protein 1 and protection from P. falciparum malaria. Infection and Immunity 75, 2415-2420.

Makobongo, M. O., Keegan, B., Long, C. A. and Miller, L. H. (2006). Immunization of Aotus monkeys with recombinant cysteine-rich interdomain region 1 alpha protects against severe disease during Plasmodium falciparum reinfection. Fournal of Infectious Diseases 193, 731-740.

Marchiafava, E. and Bignami, A. (1894). On summer-autumn malaria fevers. In Two Monographs on Malaria and the Parasites of Malarial Fevers (ed. Marchiafava, E.), pp. 1-232. New Sydenham Society, London. Marsh, K. (1992). Malaria-a neglected disease? Parasitology, 104, S53S69.

Marsh, K. and Howard, R. J. (1986). Antigens induced on erythrocytes by Plasmodium falciparum: expression of diverse and conserved determinants. Science 231, 150-153.

Marsh, K., Otoo, L., Hayes, R. J., Carson, D. C. and Greenwood, B. M. (1989).Antibodies to blood stage antigens of Plasmodium falciparum in rural gambians and their relation to protection against infection. Transactions of the Royal Society of Tropical Medicine and Hygiene 83, 293-303.

Merrick, C. J., Huttenhower, C., Buckee, C., Amambua-Ngwa, A., Gomez-Escobar, N., Walther, M., Conway, D. J. and Duraisingh, M. T. (2012). Epigenetic dysregulation of virulence gene expression in severe Plasmodium falciparum malaria. Fournal of Infectious Diseases 205, 1593-1600.

Molineaux, L., Diebner, H. H., Eichner, M., Collins, W. E., Jeffery, G. M. and Dietz, K. (2001). Plasmodium falciparum parasitaemia described by a new mathematical model. Parasitology 122, 379-391.

Moll, K., Pettersson, F., Vogt, A. M., Jonsson, C., Rasti, N., Ahuja, S., Spangberg, M., Mercereau-Puijalon, O., Arnot, D. E., Wahlgren, M. and Chen, Q. (2007). Generation of cross-protective antibodies against Plasmodium falciparum sequestration by immunization with an erythrocyte membrane protein 1-duffy binding-like 1 alpha domain. Infection and Immunity 75, 211-219.

Moxon, C. A., Wassmer, S.C., Milner, D.A., Jr., Chisala, N. V., Taylor, T.E., Seydel, K. B., Molyneux, M.E., Faragher, B., Esmon, C. T., Downey, C., Toh, C.H., Craig, A.G. and Heyderman, R. S. (2013). Loss of endothelial protein C receptors links coagulation and inflammation to parasite sequestration in cerebral malaria in African children. Blood 122, 842-851.

Newbold, C., Warn, P., Black, G., Berendt, A., Craig, A., Snow, B. Msobo, M., Peshu, N. and Marsh, K. (1997). Receptor-specific adhesion and clinical disease in Plasmodium falciparum. American Yournal of Tropical Medicine and Hygiene 57, 389-398.

Niang, M., Bei, A. K., Madnani, K. G., Pelly, S., Dankwa, S., Kanjee, U., Gunalan, K., Amaladoss, A., Yeo, K.P., Bob, N.S., Malleret, B., Duraisingh, M. T. and Preiser, P. R. (2014). STEVOR is a Plasmodium falciparum erythrocyte binding protein that mediates merozoite invasion and rosetting. Cell Host Microbe 16, 81-93.

Nielsen, M. A., Staalsoe, T., Kurtzhals, J. A., Goka, B. Q., Dodoo, D., Alifrangis, M., Theander, T. G., Akanmori, B. D. and Hviid, L. (2002). Plasmodium falciparum variant surface antigen expression varies between isolates causing severe and nonsevere malaria and is modified by acquired immunity. Fournal of Immunology 168, 3444-3450. 
Nielsen, M. A., Vestergaard, L.S., Lusingu, J., Kurtzhals, J. A., Giha, H. A., Grevstad, B., Goka, B. Q., Lemnge, M. M., Jensen, J. B., Akanmori, B. D., Theander, T. G., Staalsoe, T. and Hviid, L. (2004). Geographical and temporal conservation of antibody recognition of Plasmodium falciparum variant surface antigens. Infection and Immunity 72, 3531-3535.

Normark, J., Nilsson, D., Ribacke, U., Winter, G., Moll, K., Wheelock, C. E., Bayarugaba, J., Kironde, F., Egwang, T. G., Chen, Q., Andersson, B. and Wahlgren, M. (2007). PfEMP1DBL1alpha amino acid motifs in severe disease states of Plasmodium falciparum malaria. Proceedings of the National Academy of Sciences of the United States of America 104, 15835-15840.

Nunes-Silva, S., Gangnard, S., Vidal, M., Vuchelen, A., Dechavanne, S., Chan, S., Pardon, E., Steyaert, J., Ramboarina, S., Chene, A. and Gamain, B. (2014). Llama immunization with fulllength VAR2CSA generates cross-reactive and inhibitory single-domain antibodies against the DBL1X domain. Scientific Reports 4, 7373.

Obiero, J. M., Shekalaghe, S., Hermsen, C. C., Mpina, M., Bijker, E. M., Roestenberg, M., Teelen, K., Billingsley, P. F., Sim, B. K., James, E. R., Daubenberger, C. A., Hoffman, S. L., Abdulla, S., Sauerwein, R. W. and Scholzen, A. (2015). Impact of malaria pre-exposure on anti-parasite cellular and humoral immune responses after controlled human malaria infection. Infection and Immunity 83, 2185-2196. Ochola, L. B., Siddondo, B. R., Ocholla, H., Nkya, S., Kimani, E. N., Williams, T. N., Makale, J. O., Liljander, A., Urban, B. C., Bull, P. C., Szestak, T., Marsh, K. and Craig, A. G. (2011). Specific receptor usage in Plasmodium falciparum cytoadherence is associated with disease outcome. PLoS One 6, e14741.

Oguariri, R. M., Mattei, D., Tena-Tomas, C., Uhlemann, A.C., Kremsner, P. G. and Kun, J. F. (2003). Recombinant Duffy bindinglike-alpha domains of Plasmodium falciparum erythrocyte membrane protein 1 elicit antibodies in rats that recognise conserved epitopes. Parasitology Research 90, 467-472.

Otto, T.D., Rayner, J.C., Bohme, U., Pain, A., Spottiswoode, N., Sanders, M., Quail, M., Ollomo, B., Renaud, F., Thomas, A.W., Prugnolle, F., Conway, D. J., Newbold, C. and Berriman, M. (2014). Genome sequencing of chimpanzee malaria parasites reveals possible pathways of adaptation to human hosts. Nature Communications 5, 4754

Patarroyo, M. E., Alba, M. P., Curtidor, H., Vanegas, M., Almonacid, H. and Patarroyo, M. A. (2014). Using the PfEMP1 head structure binding motif to deal a blow at severe malaria. PLoS ONE 9, e88420.

Rask, T. S., Hansen, D. A., Theander, T. G., Gorm Pedersen, A. and Lavstsen, T. (2010). Plasmodium falciparum erythrocyte membrane protein 1 diversity in seven genomes - divide and conquer. PLoS Computational Biology 6, pii e1000933.

Rathore, U., Kesavardhana, S., Mallajosyula, V.V. and Varadarajan, R. (2014). Immunogen design for HIV-1 and influenza. Biochimica et Biophysica Acta 1844, 1891-1906.

Reeder, J. C., Rogerson, S. J., Al-Yaman, F., Anders, R. F., Coppel, R. L., Novakovic, S., Alpers, M. P. and Brown, G. V. (1994). Diversity of agglutinating phenotype, cytoadherence, and rosette-forming characteristics of Plasmodium falciparum isolates from Papua New Guinean children. American Fournal of Tropical Medicine and Hygiene 51, 45-55.

Roberts, D. J., Craig, A. G., Berendt, A. R., Pinches, R., Nash, G., Marsh, K. and Newbold, C. I. (1992). Rapid switching to multiple antigenic and adhesive phenotypes in malaria. Nature 357, 689-692.

Robinson, B. A., Welch, T. L. and Smith, J. D. (2003). Widespread functional specialization of Plasmodium falciparum erythrocyte membrane protein 1 family members to bind CD36 analysed across a parasite genome. Molecular Microbiology 47, 1265-1278.

Roca-Feltrer, A., Carneiro, I., Smith, L., Schellenberg, J. R., Greenwood, B. and Schellenberg, D. (2010). The age patterns of severe malaria syndromes in sub-Saharan Africa across a range of transmission intensities and seasonality settings. Malaria fournal 9, 282

Rottmann, M., Lavstsen, T., Mugasa, J. P., Kaestli, M., Jensen, A. T., Muller, D., Theander, T. and Beck, H. P. (2006). Differential expression of var gene groups is associated with morbidity caused by Plasmodium falciparum infection in Tanzanian children. Infection and Immunity 74, 3904-3911

Rovira-Vallbona, E., Monteiro, I., Bardaji, A., Serra-Casas, E., Neafsey, D. E., Quelhas, D., Valim, C., Alonso, P., Dobano, C., Ordi, J., Menendez, C. and Mayor, A. (2013). VAR2CSA signatures of high Plasmodium falciparum parasitemia in the placenta. PLoS ONE 8, e69753.

Rowe, A., Obeiro, J., Newbold, C. I. and Marsh, K. (1995). Plasmodium falciparum rosetting is associated with malaria severity in Kenya. Infection and Immunity 63, 2323-2326.
Rowe, J. A., Moulds, J. M., Newbold, C. I. and Miller, L. H. (1997). P. falciparum rosetting mediated by a parasite-variant erythrocyte membrane protein and complement-receptor 1. Nature 388, 292-295.

Rowe, J. A., Claessens, A., Corrigan, R. A. and Arman, M. (2009). Adhesion of Plasmodium falciparum-infected erythrocytes to human cells: molecular mechanisms and therapeutic implications. Expert Reviews in Molecular Medicine 11, e16.

Salanti, A., Staalsoe, T., Lavstsen, T., Jensen, A. T., Sowa, M. P., Arnot, D. E., Hviid, L. and Theander, T. G. (2003). Selective upregulation of a single distinctly structured var gene in chondroitin sulphate A-adhering Plasmodium falciparum involved in pregnancy-associated malaria. Molecular Microbiology 49, 179-191.

Saul, A. (1999). The role of variant surface antigens on malaria-infected red blood cells. Parasitology Today 15, 455-457.

Severins, M., Klinkenberg, D. and Heesterbeek, H. (2012). How selection forces dictate the variant surface antigens used by malaria parasites. Fournal of the Royal Society Interface 9, 246-260.

Smith, J. D. (2014). The role of PfEMP1 adhesion domain classification in Plasmodium falciparum pathogenesis research. Molecular and Biochemical Parasitology 195, 82-87.

Smith, J. D., Chitnis, C. E., Craig, A. G., Roberts, D. J., HudsonTaylor, D. E., Peterson, D.S., Pinches, R., Newbold, C. I. and Miller, L. H. (1995). Switches in expression of Plasmodium falciparum var genes correlate with changes in antigenic and cytoadherent phenotypes of infected erythrocytes. Cell 82, 101-110.

Smith, J. D., Kyes, S., Craig, A. G., Fagan, T., Hudson-Taylor, D. Miller, L. H., Baruch, D. I. and Newbold, C. I. (1998). Analysis of adhesive domains from the A4VAR Plasmodium falciparum erythrocyte membrane protein-1 identifies a CD36 binding domain. Molecular and Biochemical Parasitology 97, 133-148.

Smith, J. D., Craig, A. G., Kriek, N., Hudson-Taylor, D., Kyes, S., Fagan, T., Pinches, R., Baruch, D. I., Newbold, C. I. and Miller, L. H. (2000). Identification of a Plasmodium falciparum intercellular adhesion molecule-1 binding domain: a parasite adhesion trait implicated in cerebral malaria. Proceedings of the National Academy of Sciences of the United States of America 97, 1766-1771.

Stevenson, L., Huda, P., Jeppesen, A., Laursen, E., Rowe, J. A., Craig, A., Streicher, W., Barfod, L. and Hviid, L. (2014). Investigating the function of $\mathrm{F}$-specific binding of IgM to Plasmodium falciparum erythrocyte membrane protein 1 mediating erythrocyte rosetting. Cellular Microbiology 17, 819-831.

Su, X., Heatwole, V. M., Wertheimer, S. P., Guinet, F., Herrfeldt, J. A., Peterson, D. S., Ravetch, J. A. and Wellems, T. E. (1995). The large diverse gene family var encodes proteins involved in cytoadherence and antigenic variation of Plasmodium falciparum-infected erythrocytes. Cell 82, 89-100.

Taylor, T.E., Fu, W. J., Carr, R. A., Whitten, R. O., Mueller, J. S., Fosiko, N. G., Lewallen, S., Liomba, N. G. and Molyneux, M.E. (2004). Differentiating the pathologies of cerebral malaria by postmortem parasite counts. Nature Medicine 10, 143-145.

Tebo, A. E., Kremsner, P. G., Piper, K. P. and Luty, A. J. (2002). Low antibody responses to variant surface antigens of Plasmodium falciparum are associated with severe malaria and increased susceptibility to malaria attacks in Gabonese children. American Fournal of Tropical Medicine and Hygiene 67, 597-603.

Tembo, D. L., Nyoni, B., Murikoli, R. V., Mukaka, M., Milner, D. A., Berriman, M., Rogerson, S. J., Taylor, T.E., Molyneux, M.E., Mandala, W. L., Craig, A.G. and Montgomery, J. (2014). Differential PfEMP1 expression is associated with cerebral malaria pathology. PLoS Pathogens 10, e1004537.

Turner, L., Lavstsen, T., Berger, S. S., Wang, C. W., Petersen, J. E., Avril, M., Brazier, A. J., Freeth, J., Jespersen, J. S., Nielsen, M. A., Magistrado, P., Lusingu, J., Smith, J. D., Higgins, M.K. and Theander, T.G. (2013). Severe malaria is associated with parasite binding to endothelial protein $\mathrm{C}$ receptor. Nature 498, 502-505.

van Noort, S.P., Nunes, M. C., Weedall, G. D., Hviid, L. and Gomes, M. G. (2010). Immune selection and within-host competition can structure the repertoire of variant surface antigens in Plasmodium falciparum - a mathematical model. PLoS ONE 5, e9778.

Vigan-Womas, I., Guillotte, M., Juillerat, A., Vallieres, C., LewitBentley, A., Tall, A., Baril, L., Bentley, G. A. and MercereauPuijalon, O. (2011). Allelic diversity of the Plasmodium falciparum erythrocyte membrane protein 1 entails variant-specific red cell surface epitopes. PLoS ONE 6, e16544

Vigan-Womas, I., Guillotte, M., Juillerat, A., Hessel, A., Raynal, B., England, P., Cohen, J. H., Bertrand, O., Peyrard, T., Bentley, G. A. Lewit-Bentley, A. and Mercereau-Puijalon, O. (2012). Structural 
basis for the ABO blood-group dependence of Plasmodium falciparum rosetting. PLoS Pathogens 8, e1002781.

Wang, C.W., Hermsen, C.C., Sauerwein, R.W., Arnot, D.E., Theander, T. G. and Lavstsen, T. (2009). The Plasmodium falciparum var gene transcription strategy at the onset of blood stage infection in a human volunteer. Parasitology International 58, 478-480.

Warimwe, G. M., Keane, T.M., Fegan, G., Musyoki, J. N., Newton, C. R., Pain, A., Berriman, M., Marsh, K. and Bull, P. C. (2009). Plasmodium falciparum var gene expression is modified by host immunity. Proceedings of the National Academy of Sciences of the United States of America 106, 21801-21806.

Warimwe, G. M., Fegan, G., Musyoki, J. N., Newton, C. R., Opiyo, M., Githinji, G., Andisi, C., Menza, F., Kitsao, B., Marsh, K. and Bull, P. C. (2012). Prognostic indicators of life-threatening malaria are associated with distinct parasite variant antigen profiles. Science Translational Medicine 4, 129 ra45.

Warimwe, G. M., Fegan, G., Musyoki, J. N., Newton, C. R., Opiyo, M., Githinji, G., Andisi, C., Menza, F., Kitsao, B., Marsh, K. and Bull, P. C. (2012). Prognostic indicators of life-threatening malaria are associated with distinct parasite variant antigen profiles. Science Translational Medicine 4, 129-145.

Warimwe, G. M., Recker, M., Kiragu, E.W., Buckee, C. O., Wambua, J., Musyoki, J. N., Marsh, K. and Bull, P. C. (2013). Plasmodium falciparum var gene expression homogeneity as a marker of the host-parasite relationship under different levels of naturally acquired immunity to malaria. PLoS ONE 8, e70467.

Whitrow, M. (1990). Wagner-Jauregg and fever therapy. Medical History 34, 294-310.

Wilson, D. B., Garnham, P.C. and Swellengrebel, N.H. (1950). A review of hyperendemic malaria. Tropical Diseases Bulletin 47, 677-698.

Yone, C. L., Kremsner, P. G. and Luty, A. J. (2005). Immunoglobulin G isotype responses to erythrocyte surface-expressed variant antigens of Plasmodium falciparum predict protection from malaria in African children. Infection and Immunity 73, 2281-2287.

Zilversmit, M. M., Chase, E. K., Chen, D. S., Awadalla, P., Day, K. P. and McVean, G. (2013). Hypervariable antigen genes in malaria have ancient roots. BMC Evolutionary Biology 13, 110. 